\title{
Comparing novelty of designs from biological-inspiration with those from brainstorming
}

Keshwani, Sonal; Lenau, Torben Anker; Ahmed-Kristensen, Saeema; Chakrabarti, Amaresh

Published in:

Journal of Engineering Design

Link to article, DOI:

$10.1080 / 09544828.2017 .1393504$

Publication date:

2017

Document Version

Peer reviewed version

Link back to DTU Orbit

\section{Citation (APA):}

Keshwani, S., Lenau, T. A., Ahmed-Kristensen, S., \& Chakrabarti, A. (2017). Comparing novelty of designs from biological-inspiration with those from brainstorming. Journal of Engineering Design, 28(10-12), 654-680. DOI: 10.1080/09544828.2017.1393504

\section{General rights}

Copyright and moral rights for the publications made accessible in the public portal are retained by the authors and/or other copyright owners and it is a condition of accessing publications that users recognise and abide by the legal requirements associated with these rights.

- Users may download and print one copy of any publication from the public portal for the purpose of private study or research.

- You may not further distribute the material or use it for any profit-making activity or commercial gain

- You may freely distribute the URL identifying the publication in the public portal 


\section{Comparing novelty of designs from biological-inspiration with those from brainstorming}

Sonal Keshwani, Torben Anker Lenau, Saeema Ahmed-Kristensen \& Amaresh Chakrabarti

To cite this article:

Sonal Keshwani, Torben Anker Lenau, Saeema Ahmed-Kristensen \& Amaresh

Chakrabarti (2017): Comparing novelty of designs from biological-inspiration with those from

brainstorming, Journal of Engineering Design, DOI: 10.1080/09544828.2017.1393504

Published online 1. Nov 2017 


\title{
Comparing novelty of designs from biological-inspiration with those from brainstorming
}

\begin{abstract}
This research aims to understand the significance of biologicalanalogies in fostering novelty by comparing biological-analogies with other design methods for idea generation. Among other design methods, brainstorming was chosen here as benchmark. Four studies were conducted to compare: (i) the levels of abstraction at which concepts were ideated using biological inspiration (represented using biocards) with that using traditional brainstorming; and (ii) the novelty of concepts produced by using these two design methods. Concepts produced in these studies were evaluated for levels of abstraction at which they were ideated, average novelty, and proportion of high-novelty concepts. Results suggest that concepts generated using biocards were ideated at higher abstraction levels than those using brainstorming, but neither were at the highest abstraction levels. The average novelty of concepts produced using biocards was found to be greater than that using brainstorming; however, no statistically significant difference was found in the proportion of high-novelty concepts. We suspect the lack of biological knowledge and cultural difference among the subjects involved in our studies as the two reasons behind the results. The results demonstrate that the design methods substantially influence the novelty of concepts generated, while indicating the need for better training in effective use of biological-analogies.
\end{abstract}

Keywords: Conceptual design, creativity; creative-design; design methods; biologically inspired design;

\section{Introduction}

Creative products are known to positively influence the success of companies that produce these products (Ottosson 1995; Molina et al. 1995). This provides a major motivation to researchers for developing better design methods for enhancing creativity in products. Creativity is an inspirational force that generates new ideas or produces 
novel combinations of existing ideas, leading to further solutions or deeper understanding (Pahl and Beitz 2007). 'Novelty' has frequently been identified as one of the main, overarching characteristics of creativity (Rhodes 1961; Sarkar and Chakrabarti 2008, 2011; Chulvi et al. 2012) and is defined as something new, original or unexpected (Sternberg and Lubart 1999; Sarkar and Chakrabarti 2011).

Numerous researchers (Bhushan 2016; Deldin and Schuknecht 2014; Vincent et al. 2006) have reported the positive influences of biological-analogies (biomimetics) and brainstorming (Chulvi et al. 2012; Al-khatib 2012; Taleb, Hamza and Wefky 2013) - two well-known design methods of creativity - on novelty of concepts produced. However, there is hardly any study that compares which of these two methods, namely biomimetics and brainstorming, has a greater influence on novelty. Comparing this is important because while brainstorming has been largely systematised by researchers by introducing its variations and rules for those variations, biomimetics - which is not as systematic as brainstorming, is witnessing an exponential increase in its use, as reflected by the increase in its publications and patents (Lepora, Verschure, and Prescott 2013). Because of its substantial popularity, brainstorming can act as a worthy benchmark for comparison and assessment of the potential for biomimetic methods such as biocards (Lenau et al. 2010).

Further, researchers have also acknowledged that the higher the level of abstraction at which concepts are ideated, the higher is their novelty (Sartori, Pal, and Chakrabarti 2010; Srinivasan and Chakrabarti 2010). However, studies are relatively few that have compared the influence of the two methods on the levels of abstraction at which 
concepts are ideated. Comparing levels of abstraction has been adopted in this work as an indicator for assessing as to which of these methods better support novelty.

The work presented in this paper attempts to address the above two research gaps, at the conceptual-stage of designing in the domain of technical-products.

\section{Literature Review}

In this section, literature is reviewed in the following areas: (i) brainstorming and biological-inspiration (Section 2.1); and (ii) levels of abstraction at which concepts are ideated (Section 2.2).

\subsection{Design Methods for Novel Idea Generation}

Nature is a rich source for novel idea-generation. Biomimetics is an area of research that takes inspiration, or uses analogies, from nature to solve problems in the engineeringdomain. Numerous studies are reported where biomimetics offered promising solutions to engineering problems (Etoundi, Burgess, and Vaidyanathan 2013; Bhushan 2016). Frameworks for selection of energy efficient (Sara and Noureddine 2015) and material efficient biological-analogies for a given problem have been proposed (O'Rourke et al. 2015).Researchers combined biomimetics with TRIZ to generate design-solutions (Vincent et al. 2006; Craig et al. 2008; Baldussu and Cascini 2015). Computational tools to search for biological-analogies have also been proposed (Chakrabarti et al. 2005; Vattam et al. 2011; Cheong and Shu 2012; Kaiser, Hashemi, and Lindemann2012; Murphy et al. 2013; Deldin and Schuknecht 2014; Tsenn et al. 2016), and comparative analyses of these tools, on various parameters, have been carried out (Appio et al. 2016). A related area of research aims to understand the cognitive processes underlying biomimetics; for instance, Sartori, Pal and Chakrabarti (2010) studied twenty industrial- 
cases of biologically inspired product-development from literature, and found that most transfers in these cases took place at the lower levels of abstraction; Helms and Goel (2012) found that biological-analogies had been used for identifying, formulating, and transforming design problems very early in the design process. Kennedy et al. (2015) proposed a framework and best practices to integrate biology, design, and engineering for teaching sustainable innovation. The variety of research efforts in biomimetics, as illustrated by the examples above, indicates its perceived potential in supporting generation of novel and valuable designs.

As design methods influence novelty (López-Mesa et al. 2011; Chulvi et al. 2012), it is important to assess which methods produce more novel designs. However, except for the work of Keshwani et al. (2013) (as discussed in Section 4), no studies seem to have compared the influence of biological-analogies with that of other ideation methods on novelty of concepts produced. The closest is the work of Nelson, Wilson and Yen (2009), who observed a greater tendency towards innovative design among students who attended a course on biologically inspired design than those who did not.

An objective of this work, therefore, is to compare the influence of using biomimetics with that using brainstorming, on novelty of designs. 'Brainstorming involves generating a large number of ideas or solutions to a problem with a focus on quantity of ideas. During this process, no ideas are evaluated; in fact unusual ideas are welcomed'(Herring, Jones, and Bailey 2009). Brainstorming is used as a benchmark in this study as it is often referred to as, 'the mother of all idea generation techniques' (Osborn et al. 1971); it is among the most well-known tools for creative problem-solving (Fernald and Nickolenko, 1993). According to current literature, it has the potential to 
improve group idea-generation (Isaksen 1998; Al-khatib 2012;Taleb, Hamza, and Wefky 2013) and support generation of more novel designs than functional-analysis or SCAMPER (Chulvi et al. 2012).

\subsection{Levels of Abstraction at Which Concepts Are Ideated}

According to Srinivasan and Chakrabarti (2010) and Sarkar and Chakrabarti (2011), the higher the levels of abstraction at which concepts (i.e. designs) are ideated, the higher is the novelty of the concepts produced. Therefore, comparing the levels of abstraction of the concepts produced using biological-analogies with those generated using brainstorming can provide insights into the effectiveness of these methods in supporting novelty. In order to describe a concept at different abstraction levels, the SAPPhIRE model of causality has been used in this work.

Chakrabarti et al. (2005) reviewed different models of causality and proposed the SAPPhIRE model, which provides a richer description of causal relations than by the causal models reviewed by them in their work. This model was originally developed for supporting product design by providing causal descriptions of biological and technical systems as stimuli for inspiring ideation. The model was empirically validated, and was found to be a natural way of how engineers design technical-concepts (Srinivasan and Chakrabarti 2010) and embodiments (Ranjan, Srinivasan and Chakrabarti 2012). The

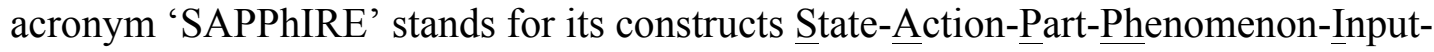
oRgan-Effect.

Srinivasan and Chakrabarti (2010) describe this model as follows: 'Components and interfaces that comprise a system and its environment (parts) have some properties and conditions (organs). When the system and the environment are not in equilibrium 
with each other, there is a transfer of physical quantities in the form of a material, energy or signal (input) across the system boundary. These physical quantities, in combination with relevant properties and conditions, activate a principle (physical-effect). This principle is responsible for an interaction (physical-phenomenon) between the system and the environment. The interaction between the system and the environment changes various properties of the system and the environment (state-change). The change in properties can be interpreted at a higher level of abstraction (action).' Figure1 illustrates the logical dependency among the constructs in the SAPPhIRE model and the digits 1-7 in parenthesis denote the hierarchy in the SAPPhIRE abstraction levels. For an example explaining the SAPPhIRE model, see Srinivasan and Chakrabarti (2010).

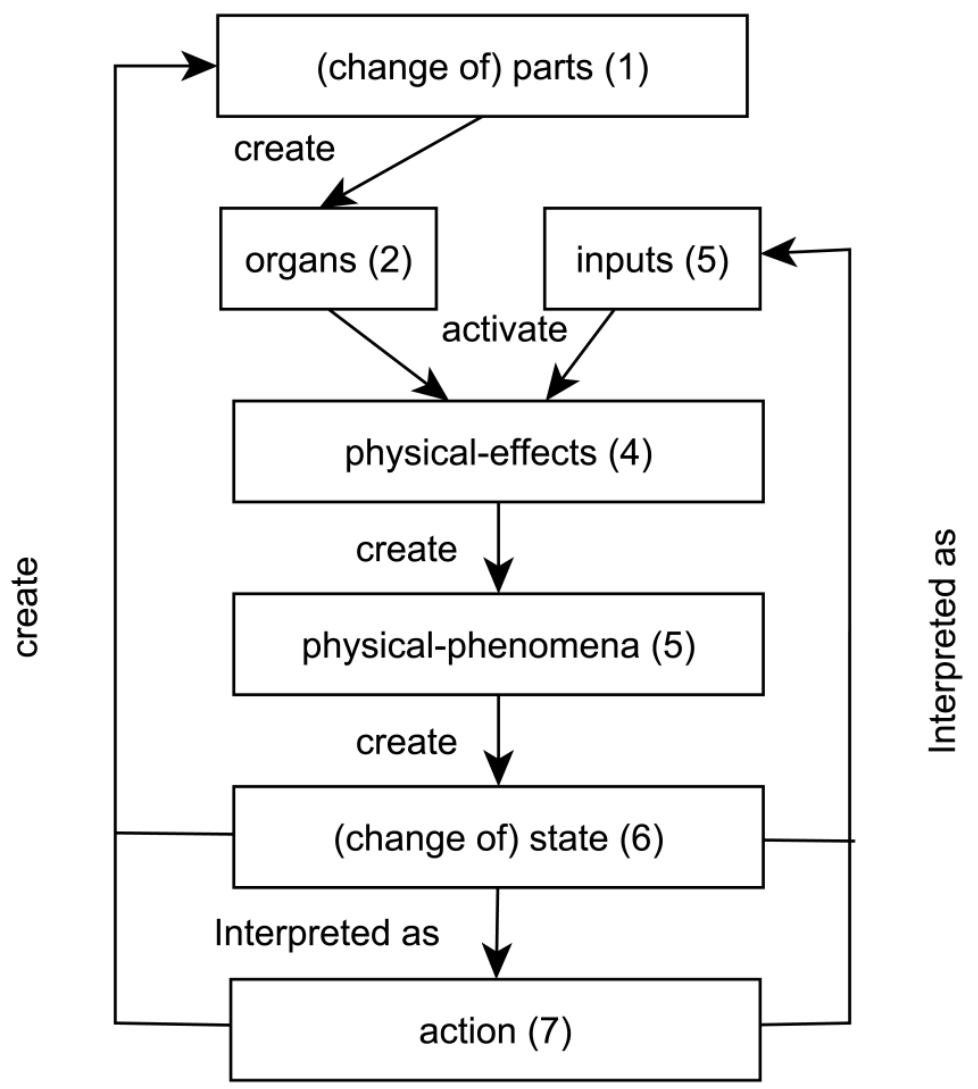

Figure 1. The SAPPhIRE model (Srinivasan and Chakrabarti 2010) 
Sartori et al. (2010) demonstrated that providing the SAPPhIRE model-based descriptions and guidelines, as opposed to natural-language descriptions and genericguidelines, for transfer of biological-analogies, better supported transfer of biologicalstimuli to technical-designs by encouraging ideation at higher abstraction-levels. Use of the SAPPhIRE-based guidelines resulted in a shift in biomimetic-transfer from largely part and organ (i.e. lower) levels to organ and state-change (i.e. higher) levels. Similar trends, of ideation at higher abstraction-levels leading to greater novelty, were also observed by Srinivasan and Chakrabarti (2010) in conceptual-design for technicalproducts where no methods or stimuli were given. However, whether similar trends hold good in stimuli-led ideation, especially for biological-stimuli, is not explored.

Another objective of this research, therefore, is to compare the abstraction-levels at which concepts produced using brainstorming are ideated with the abstraction-levels at which concepts produced using biological-analogies are ideated.

\section{Research Objectives and Hypotheses}

This section presents the key concepts from the literature reviewed in Section 2 and subsequently presents the research objectives and hypotheses.

The key concepts from Section 2.1 are as follows. Literature reports that both biomimetics and brainstorming produce novel designs. There are studies that reported the influence of design methods on novelty of concepts produced. There is also evidence that biomimetics has received widespread attention from researchers and designers. However, the effectiveness of these two approaches in supporting novelty has not been compared. Therefore, one research objective $\mathrm{O}$ of this work is formulated as follows: 
O: To compare the novelty of designs generated using biological-analogies with the novelty of designs generated using brainstorming.

We now formulate the Hypothesis $\mathrm{H}$ associated with Objective O. According to researchers, designs produced using analogies from conceptually different domains are more novel than those produced using analogies from conceptually close domains (Ward, 1998; Bonnardel, 2000; Dahl and Moraeu, 2002). As biological- and engineeringdomains are substantially different from each other, engineering-designs inspired by the biological-domain should be more novel than engineering-designs inspired by an engineering-domain, e.g., designs produced using brainstorming which typically relies on the engineering-knowledge of its participants for developing engineering-designs. Therefore, hypothesis $\mathrm{H}$ is formulated as follows:

$\mathrm{H}$ : Concepts produced using biological-analogies will have a higher level of novelty than concepts produced using brainstorming.

The key points from Section 2.2 are as follows: Novelty of concepts is positively influenced by the levels of abstraction at which the concepts are ideated. Comparing the levels of abstraction of the concepts produced using biological-analogies with those using brainstorming would provide insights as to which of these methods could support greater novelty in ideation. Therefore, another objective o of this research is stated as follows:

o: To compare the levels of abstraction at which concepts are ideated using biological-analogies with those for concepts using brainstorming. 
We will now formulate the hypothesis $\mathrm{h}$ associated with objective o. Hypothesis $\mathrm{H}$ (mentioned earlier) states that biological-analogies should produce designs with greater novelty compared to those produced using brainstorming. Section 2.2 states that the levels of abstraction at which concepts are ideated positively influence novelty. On the basis of these, we hypothesize the following:

h: Concepts produced using biological-analogies will be ideated at higher levels of the SAPPhIRE abstraction than those generated using brainstorming.

\section{Prior Experiments with Biocards}

Lenau et al. (2010) defined a biocard (Figure 2) as a representation of a biologicalinspiration, which is presented to a designer as a card. According to them, a biocard describes the following:

- Biological-phenomenon: It is a phenomenon that occurs in nature.

- Biological-mechanism: It describes how and why that phenomenon occurs, thereby explicating the strategy behind the phenomena - a task that is reported to be a challenge for the designers (Helms, Vattam and Goel 2009; Cheong and Shu 2012).

- Functional-principle: It is the engineering equivalent of the biologicalmechanism. It supports in bridging the biological knowledge gap of the designers (who are engineers) - which has also been reported as a challenge in making effective use of biological-analogies (Nagel, Stone and McAdams 2010; Cheong et al. 2011). 


\section{Eyeball cleaning Organism: Mammalia}

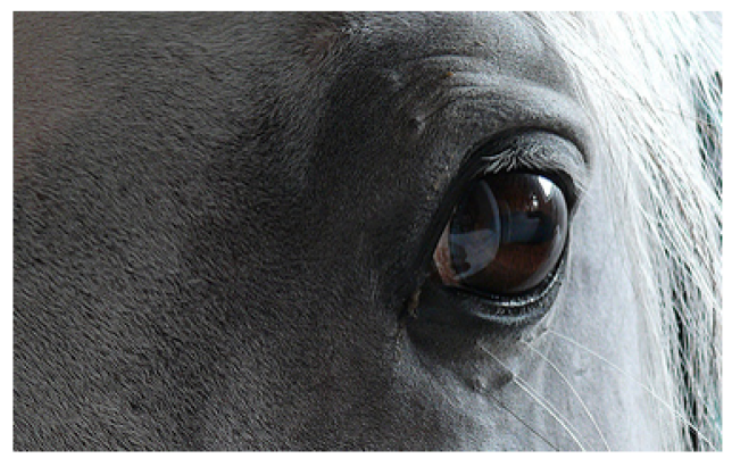

Biological phenomena: Mammalian eyes are protected from dirt by a liquid film covering the eye.

Biological mechanism: The mechanism in animal eyeball cleaning is a liquid film that adheres to dirt particles. The liquid film is regularly removed with the eyelid and replaced with fresh liquid.

Functional principle: (1) A surface is covered with an intermediate substance that adheres to unwanted matter but not to the surface. (2) The substance and the unwanted matter can be removed mechanically from the surface and (3) a new portion of the substance can be added.

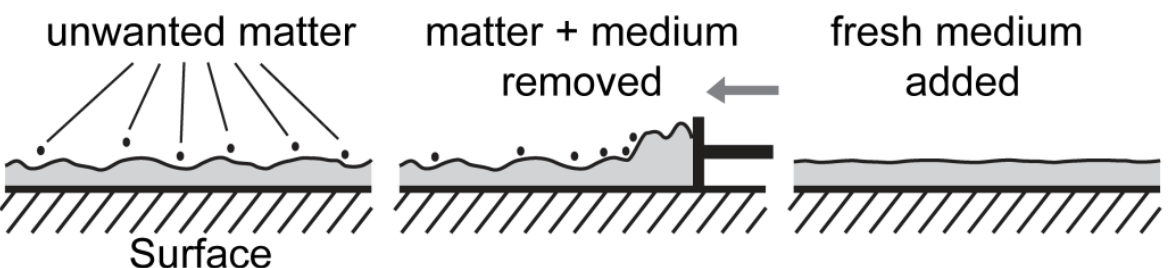

References: Braun, R.J. and Fitt, D. (2003) To minimise shear stress and to avoid solid to solid contact between the eyelid and the eye surface, the latter is covered by a thin tear film, Mathematical Medicine and Biology, 20, 1-28.

Walls, G. L. (1942) The vertebrate eye and its adaptive radiation, New Yourk, Haftner Publishing Company.

Figure 2. An example of biocard describing a cleaning principle (Lenau et al. 2010)

Keshwani et al. (2013) benchmarked the novelty of designs generated from brainstorming with those of biocards (Lenau et al. 2010) by using two novelty assessment approaches (Section 6.1.2) and suggested that biocards helped in producing more novel 
designs than brainstorming. However, the study did not have a sufficiently large sample size that could provide statistical validity. The current work uses a sample size that is double that which was used in Keshwani et al. (2013). The increased sample size allows statistical analyses of its results that could not be done in Keshwani et al. (2013).

Furthermore, the present work also analyses the influence of using biocards and brainstorming on the levels of abstraction at which concepts are ideated, which does not seem to have been reported in earlier work.

Since this work builds upon the work of Keshwani et al. (2013), biocards have been used as a means of representation of biological-analogies to designers.

\section{Research methodology}

Four studies were conducted, indicated as Study-1-4. Four teams T1-T4 were created randomly from the subjects who participated in each study. The number of subjects per team varied across the studies due to constraints in the availability of subjects at the time of conducting the studies. Table 1 provides further information on the studies.

Table1. Information on Studies

\begin{tabular}{|c|c|c|c|c|c|c|c|}
\hline \multirow[t]{2}{*}{ Study } & \multirow[t]{2}{*}{ Location } & \multicolumn{4}{|c|}{$\begin{array}{c}\text { Number of } \\
\text { subjects in a team } \\
\end{array}$} & \multirow{2}{*}{$\begin{array}{c}\text { Total } \\
\text { No. of } \\
\text { subjects }\end{array}$} & \multirow{2}{*}{$\begin{array}{c}\text { Educational-background of } \\
\text { subjects }\end{array}$} \\
\hline & & $\mathrm{T} 1$ & $\mathrm{~T} 2$ & $\mathrm{~T} 3$ & $\mathrm{~T} 4$ & & \\
\hline Study-1 & India & 4 & 4 & 3 & 4 & 15 & $\begin{array}{l}\text { first year students of Master in } \\
\text { Design course with background in } \\
\text { mechanical, industrial, } \\
\text { architecture and electronics } \\
\text { engineering }\end{array}$ \\
\hline Study-2 & Denmark & 6 & 6 & 6 & 5 & 23 & $\begin{array}{l}\text { first and second year students of } \\
\text { Master in Design and Innovation } \\
\text { course with background in design } \\
\text { and industrial engineering }\end{array}$ \\
\hline
\end{tabular}




\begin{tabular}{|l|l|l|l|l|l|l|l|} 
Study-3 & Norway & 2 & 2 & 2 & 2 & 8 & $\begin{array}{l}\text { seven students from a Master } \\
\text { course in Industrial Design } \\
\text { Engineering with backgrounds in } \\
\text { design and industrial engineering, } \\
\text { and a professor of Mechanical } \\
\text { Engineering }\end{array}$ \\
\hline Study-4 & Denmark & 4 & 4 & 3 & 4 & 15 & $\begin{array}{l}\text { twelve students from Master in } \\
\text { Design and Innovation; two } \\
\text { students from Master in } \\
\text { Mechanical Engineering and a } \\
\text { PhD student in Landscape } \\
\text { Architecture. }\end{array}$ \\
\hline
\end{tabular}

After the teams were formed, the subjects were instructed, by one of the coauthors, on how to make and use biocards. The subjects were given problems A and B (as given below) on a piece of paper, and were asked not to reveal to the other teams what the given problem was. These problems were the following:

Problem-A: To reduce the consequence of a car collision.

Problem- B: Windows that shade for sun but allow the view.

The rationale behind selection of these problems was the following. The subjects should have familiarity with the issues around the problems so that they would be able to generate concepts within the limited time given, without having to use external sources of information such as books, journals or the Internet.

As solving both the problems require some knowledge of Physics, it is worth mentioning that all the subjects involved in the studies had prior knowledge of Physics at a level equivalent to that taught in a basic Physics course in their undergraduate studies in engineering.

Each study had two inter-linked sessions - 1 and 2, as summarized in Table 2. Session 1 involved three tasks: 
- Task-1: Each team-member described the problem by drawing different scenarios in which the problem could occur. This ensured that the participants reflected on the assignment and developed a mutual understanding of the problem.

- Task-2: Each team enlisted 10-20 biological-analogies (from memory) that had been used in solving similar problems in nature. From these analogies, they selected two, which they thought had the highest potential for producing solution concepts for the given design problem.

- Task-3: For each analogy that was selected in Task-2, the subjects produced four biocards. From these four biocards, we selected two, ensuring that these biocards correctly described the biological-phenomenon, biological-mechanism and the functional-principle; and the figures drawn were clear. Thus, four biocards were selected for each team.

In session-2 the assigned problems were swapped, so each team worked on a new problem. The session involved the two tasks as follows:

- Task-4: Each team brainstormed on the new assigned problem and generated concepts in the form of concept-sketches without the use of biocards. No written rules were given to the subjects for brainstorming; however, they had been trained earlier in the semester in using brainstorming in a formal course on design methodology.

- Task-5: The biocards selected in Task-3 were given to the teams in the manner shown in Table 2. Each team used these biocards to generate concepts. 
The subjects were asked to produce as many concepts as possible, in the form of annotated sketches, for both brainstorming and biocards. It was an observational-study, conducted as an extracurricular option in laboratory-settings without intervention from researchers.

Table 2. Design of Sessions 1 and 2 in the studies S1-S4

\begin{tabular}{|c|c|c|c|c|c|c|}
\hline Session & Team & Time & T1 & T2 & T3 & T4 \\
\hline \multirow{4}{*}{$\begin{array}{c}\text { Session } \\
1\end{array}$} & Problem & (min) & B & B & $\mathbf{A}$ & $\mathbf{A}$ \\
\hline & Task-1 & 15 & $\begin{array}{l}\text { Describe } \\
\text { Problem }\end{array}$ & $\begin{array}{l}\text { Describe } \\
\text { Problem }\end{array}$ & $\begin{array}{l}\text { Describe } \\
\text { Problem }\end{array}$ & $\begin{array}{l}\text { Describe } \\
\text { Problem }\end{array}$ \\
\hline & Task-2 & 15 & $\begin{array}{c}\text { Formulate } \\
\text { search } \\
\text { terms }\end{array}$ & $\begin{array}{c}\text { Formulate } \\
\text { search } \\
\text { terms }\end{array}$ & $\begin{array}{l}\text { Formulate } \\
\text { search } \\
\text { terms }\end{array}$ & $\begin{array}{c}\text { Formulate } \\
\text { search } \\
\text { terms }\end{array}$ \\
\hline & Task-3 & 60 & $\begin{array}{l}\text { Generate } \\
\text { biocards }\end{array}$ & $\begin{array}{l}\text { Generate } \\
\text { biocards }\end{array}$ & $\begin{array}{l}\text { Generate } \\
\text { biocards }\end{array}$ & $\begin{array}{l}\text { Generate } \\
\text { biocards }\end{array}$ \\
\hline \multirow[b]{3}{*}{$\begin{array}{c}\text { Session } \\
2\end{array}$} & Problem & & $\mathbf{A}$ & $\mathbf{A}$ & B & B \\
\hline & Task-4 & 30 & Brainstorm & Brainstorm & Brainstorm & Brainstorm \\
\hline & Task-5 & 30 & $\begin{array}{c}\text { Generate } \\
\text { solutions } \\
\text { using } \\
\text { Biocards } \\
\text { from T3 } \\
\end{array}$ & $\begin{array}{c}\text { Generate } \\
\text { solutions } \\
\text { using } \\
\text { Biocards } \\
\text { from T4 } \\
\end{array}$ & $\begin{array}{c}\text { Generate } \\
\text { solutions } \\
\text { using } \\
\text { Biocards } \\
\text { from T1 }\end{array}$ & $\begin{array}{c}\text { Generate } \\
\text { solutions } \\
\text { using } \\
\text { Biocards } \\
\text { from T2 }\end{array}$ \\
\hline
\end{tabular}

There are two reasons for asking each team to produce biocards (Task-3). The process of generating biocards is for familiarization with what is meant by biologicalphenomena, biological-principle and biological-mechanism. The process of using biocards, on the other hand, is for using these as stimuli for ideation. These two processes should not be coupled; it is better if the cards used by a team were not those generated by that team. Otherwise, the biocards would bring little novelty as stimuli, since the team would already know the phenomena and principle described in the biocards. 


\section{Data analysis}

The concepts produced in design tasks 4 and 5 were first reviewed by the authors. In Team T4 in Study-3, one participant misunderstood the instructions and used biocards as the problem-definition. For instance the 'skin-tanning' biocard was used to generate ideas on new ways of getting a skin-tan instead of solving the given problem (Problem-B). It was clear that these concepts were irrelevant for this problem. Hence, these were not analysed further; the concepts produced by the other subject in the same team were, however, considered for analysis. Five other concepts (2 from biocards and 3 from brainstorming) were rejected because these were incorrect according to physical laws of nature. Table 3 presents the number of concepts considered for evaluation.

Table 3. Number of concepts evaluated for brainstorming and biocards

\begin{tabular}{|c|c|c|}
\hline Study & Task-4:Brainstorming & Task-5:Biocards \\
\hline Study-1 & 38 & 20 \\
\hline Study-2 & 25 & 23 \\
\hline Study-3 & 13 & 12 \\
\hline Study-4 & 38 & 21 \\
\hline Total & 114 & 66 \\
\hline
\end{tabular}

Section 6.1 presents three units of analysis for these concepts. Section 6.2

presents evaluation of an example concept and a design task. Section 6.3 presents interencoder reliability for the codification process.

\subsection{Units of Analysis}

This section presents the units of analysis used to test hypotheses $\mathrm{h}$ (Section 6.1.1) and $\mathrm{H}$ (Section 6.1.2). 


\subsubsection{Calculating proportion of concepts ideated at the SAPPhIRE abstraction- level ' $x$ '}

To compare the levels of abstraction at which concepts are ideated, Proportion of Concepts ideated at the SAPPhIRE abstraction-level ' $x$ ' $\left(P C_{x}\right)$ is taken as a unit of analysis. $\mathrm{PC}_{\mathrm{x}}$ (see Equation-1) is defined here as the proportion of concepts that were ideated at SAPPhIRE abstraction-level ' $\mathrm{x}$ ' in Task-t (where, $\mathrm{x} \in 0$ - 7; 0: No Ideation, 1 7: SAPPhIRE abstraction levels in Figure 1. Task-t can be either brainstorming or biocards). No ideation (henceforth abbreviated here as NI) can happen when an exactly same solution as that of the concept under consideration exists in the market.

$$
\begin{aligned}
& P C x \text { in Task }-t \\
& =\frac{\text { number of concepts idetated at abstraction level } x \text { in Task }-t}{\text { total number of concepts generated in Task }-t}
\end{aligned}
$$

\subsubsection{Evaluation of novelty}

Two complementary approaches - Approach-1 (Sarkar and Chakrabarti 2011) and Approach-2 (Srinivasan and Chakrabarti 2010) have been used for assessing novelty of concepts. The first approach is used to compute the proportion of concepts with highnovelty, while disregarding the remaining concepts. This provides an estimate of the proportion of ideas generated with substantial novelty. The second approach, in contrast, provides the average novelty of the concepts, thereby capturing the overall novelty of the concepts. Together, they help assess both the peak and the average novelty of the concept-space generated. Both these approaches use the SAPPhIRE model of causality (Section 2.2) as the basis for evaluating novelty. 
Evaluation of concepts using these approaches required a database of existingsolutions of patents, or complete products that exist(ed) in the society, for Problems A and B. The database was created by using keyword search in Google, see Appendix-A. After creating the database, SAPPhIRE models were developed for the concepts produced while carrying out the design tasks as well as those underlying the existingsolutions; these were then compared with one another using the above novelty assessment approaches. The approaches are detailed in Sections 6.1.2.1 and 6.1.2.2.

\subsubsection{Approach-1: Novelty of design concepts}

Chulvi et al. (2012) recommend the use of Moss-Metric (1966) and Sarkar and Chakrabarti's method (2008) for assessing novelty of design concepts, as these two methods had produced, in earlier instances, the best concordance of results when compared with expert evaluation as benchmark. As this study builds on the work of Keshwani et al. (2013) (as discussed in Section 4), we have used the approach used in Keshwani et al. (2013) - i.e. that proposed by Sarkar and Chakrabarti $(2008,2011)$.

Figure 3 illustrates the steps to evaluate novelty of designs using this approach. According to this approach, a concept can be classified as either having very highnovelty, high-novelty, medium-novelty, low-novelty or no-novelty. 


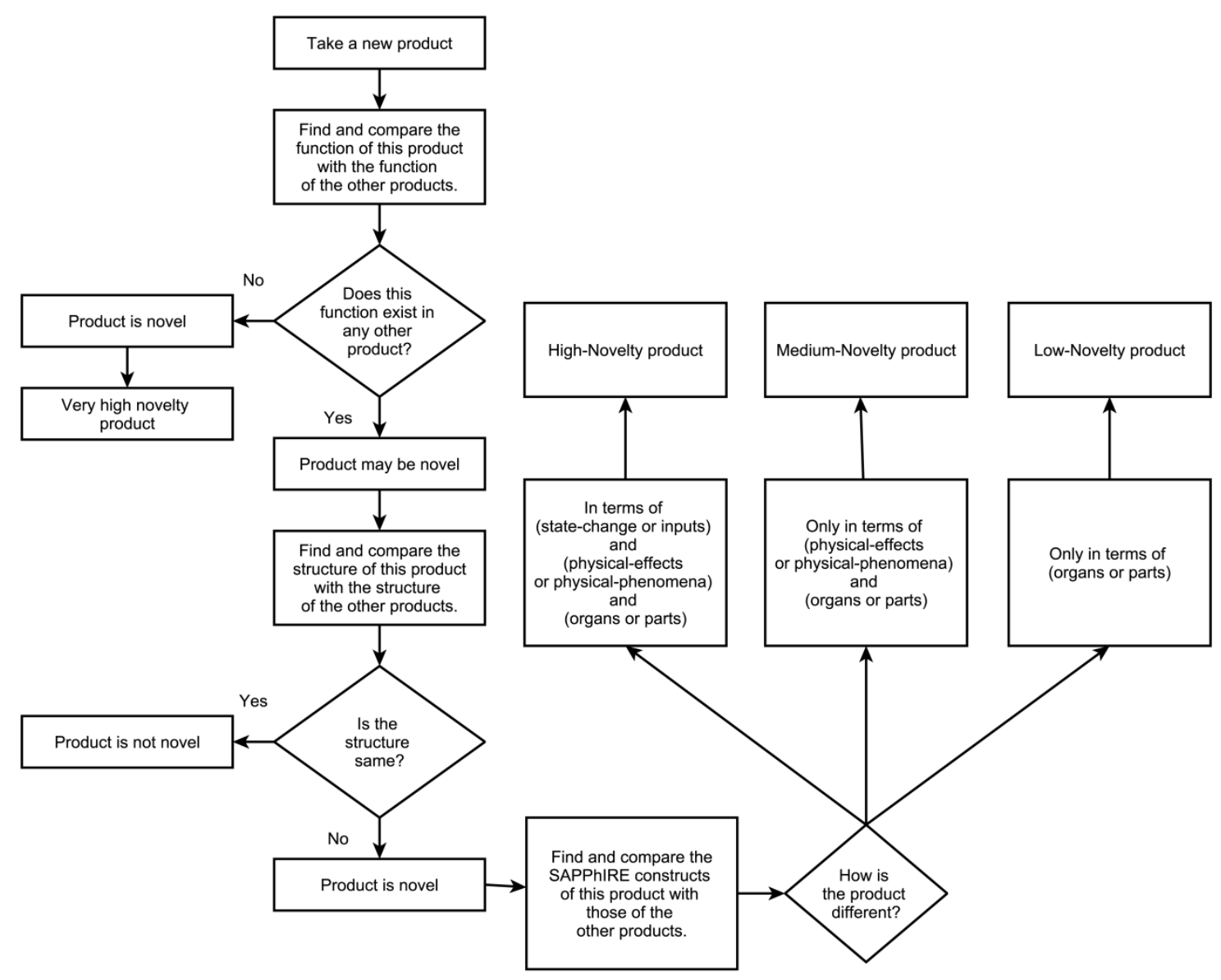

Figure 3. Steps to identify novelty of products (Sarkar and Chakrabarti, 2011)

In this work, novelty of a set of concepts is measured as the proportion of highnovelty concepts (abbreviated as $\mathrm{P}[\mathrm{HNC}]$ ) produced for a given Task-t. It is calculated using the following equation:

$$
\begin{aligned}
& P[H N C] \text { in Task }-t \\
& \qquad=\frac{\text { number of high }- \text { novelty concepts produced in Task }-t}{\text { number of concepts produced in Task }-t}
\end{aligned}
$$

We did not consider 'proportion of very high-novelty concepts' as an evaluation measure because, according to Sarkar and Chakrabarti (2011), a concept is very highlynovel only if the function satisfied by the concept did not exist in any other product. 
Since the problems were already defined in the tasks in our studies, there was little scope for producing concepts that satisfied an entirely new function. Therefore, "proportion of high-novelty concepts' was chosen as the measure of novelty. This was verified by the fact that no 'very highly-novel' concept was found for any of the tasks.

\subsubsection{Approach-2: Average novelty of concepts produced in a task}

Srinivasan and Chakrabarti (2010) developed this approach to compute Novelty of New Concept-Space (abbreviated as N[NCS]). They defined 'new concept space' as the collection of all the concepts, produced by a team in a task, which satisfy a given function. In order to assess the novelty of the $\mathrm{n}^{\text {th }}$ concept in the NCS, its SAPPhIRE abstraction-levels are compared with those of existing-solutions, and with those of all n-1 concepts in the NCS produced previously. Depending on the highest level of the SAPPhIRE abstraction at which a new-concept is different from that of the existingsolutions and the concepts in NCS, a novelty-score between 1 and 7 is awarded. Here $1,2,3,4,5,6,7$ are the novelty-scores given respectively for the difference of abstraction level occurring at part, organ, effect, phenomena, input, state-change, and action levels (Figure 1). A Novelty-score of 0 is given if the SAPPhIRE abstraction-levels of the newconcept are the same as those for existing-solutions or those in the NCS generated earlier.

The novelty of a new concept-space produced for a given Task-t is the average of novelty-scores of each concept in the NCS, calculated using the following equation: 


$$
\begin{aligned}
& N[N C S] \text { in Task }-t \\
& =\frac{\text { sum of novelty scores of each concept generated in Task }-t}{\text { number of concepts generated in Task }-t}
\end{aligned}
$$

Equations 1-3 can be applied to calculate both individual results of each team in one study and cumulative results of all four studies.

\subsection{Examples}

This section illustrates the evaluation of a concept and a design task in this work.

Figure 4 shows a concept (henceforth, termed here as $\mathrm{C}_{\text {new }}$ ) produced for Problem-A using the biocard - School of fish never collides with shark (See Figure 5). This biocard had these details (reproduced verbatim):

Title: School of Fish never collides with shark

Biological-Phenomena: In-collidable navigation skills despite the fact that fishes cannot see the shark.

Biological-Mechanism: They can sense the forces coming from shark.

Functional-Principle: Sudden change in boundary-layer [of water due to slip stream when shark approaches near the fish].

$\mathrm{C}_{\text {existing }}$ (http://searchwarp.com/swa15828.htm), found using the Internet, was the existing-solution that closely matched $\mathrm{C}_{\text {new }}$. To evaluate the novelty of $\mathrm{C}_{\text {new }}$, the SAPPhIRE models of $\mathrm{C}_{\text {new }}$ and $\mathrm{C}_{\text {existing were created and compared with each other (See }}$ Table 4). Based on this comparison, the highest level of the SAPPhIRE abstraction at which $\mathrm{C}_{\text {new }}$ and $\mathrm{C}_{\text {existing }}$ differed was 'Input', i.e. $\mathrm{C}_{\text {new }}$ was ideated at abstraction level $\mathrm{x}=$ 5. Using Approach-1 (See Figure 3), $\mathrm{C}_{\text {new }}$ was assessed to be a 'high-novelty' concept. 
Using Approach-2, the novelty-score awarded to $\mathrm{C}_{\text {new }}$ was 5 (for difference occurring at the input level).

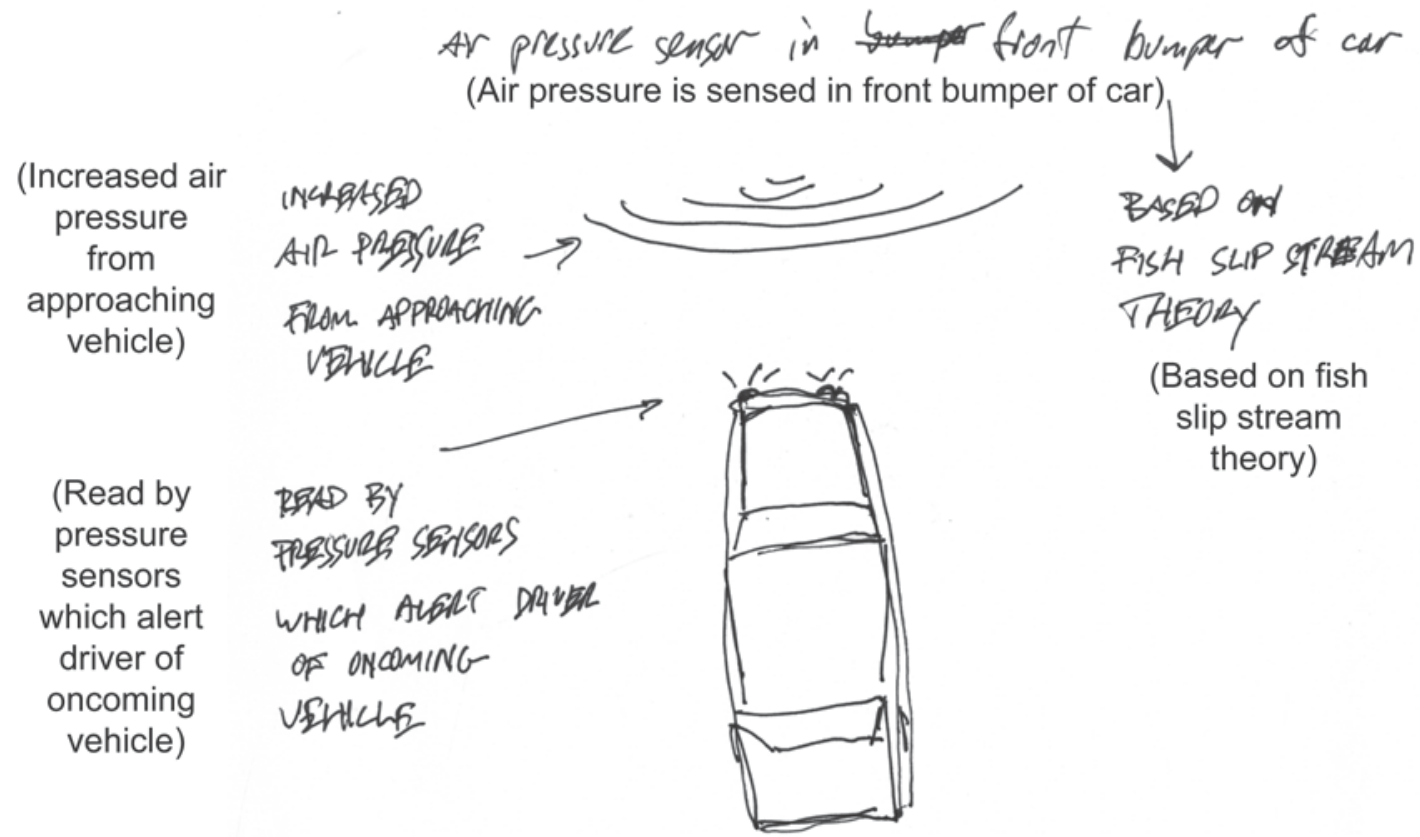

Figure 4. Concept $\mathrm{C}_{\text {new }}$ (sensor inspired by fish schools alert driver) 


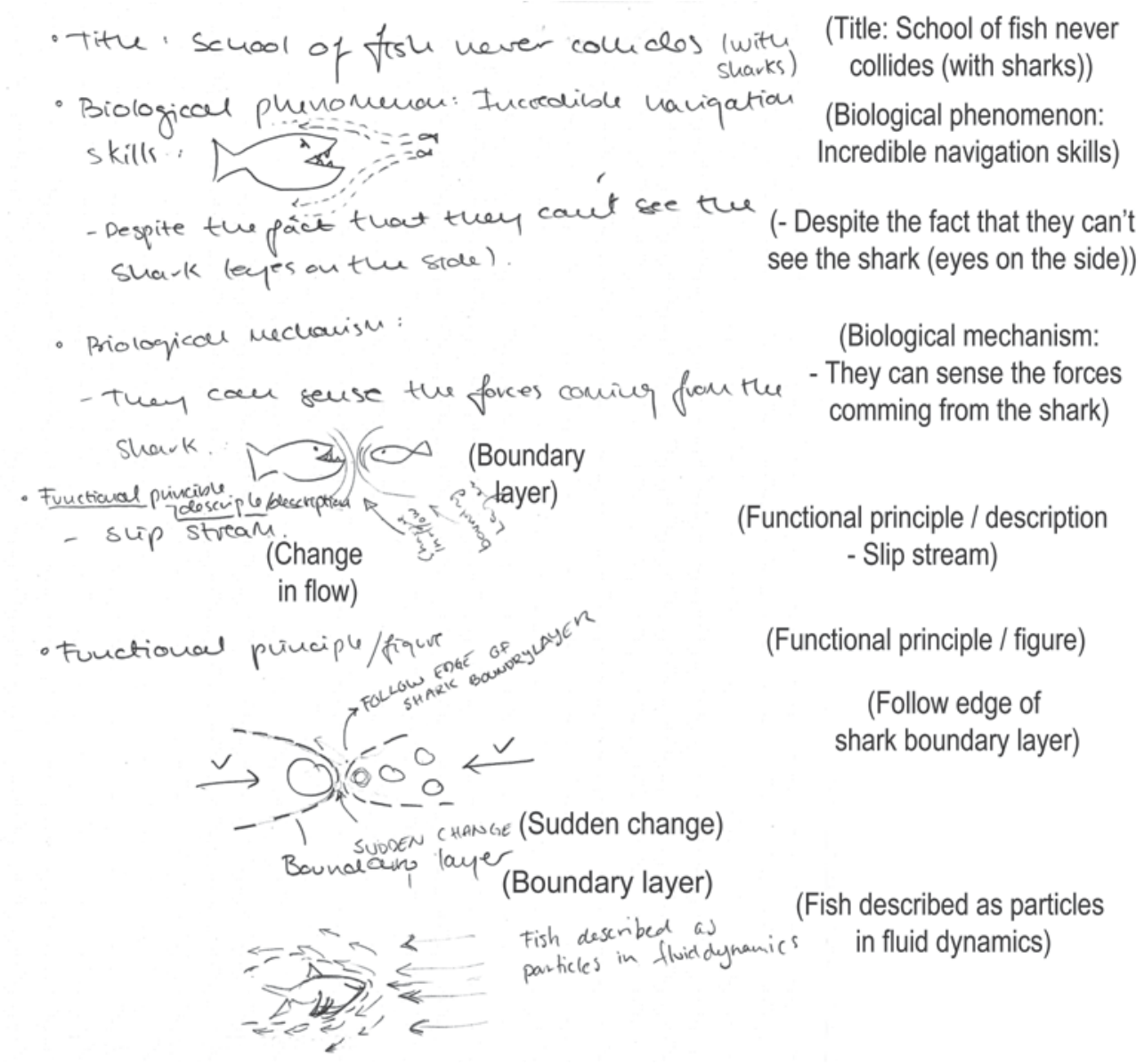

Figure 5. Biocard: School of Fish never collides with shark

Table 4. Comparison of the SAPPhIRE model of an existing-solution with a newconcept

\begin{tabular}{|c|c|c|}
\hline Concept & $\mathbf{C}_{\text {new }}$ & $\mathbf{C}_{\text {existing }}$ \\
\hline Problem A & \multicolumn{2}{|c|}{ To reduce the consequences of collision } \\
\hline Explanation & $\begin{array}{c}\text { Air velocity and pressure } \\
\text { changes for approaching } \\
\text { vehicles. A pressure sensor rings } \\
\text { an alarm to alert the driver }\end{array}$ & $\begin{array}{c}\text { Parking sensors emit and } \\
\text { detect ultrasonic waves that } \\
\text { are reflected by any obstacle } \\
\text { in their path. The sensor rings } \\
\text { an alarm to alert the driver. }\end{array}$ \\
\hline Part(1) & $\begin{array}{c}\text { Pressure Sensor mounted on the } \\
\text { front and rear side of a vehicle }\end{array}$ & $\begin{array}{c}\text { Ultrasonic parking sensors } \\
\text { mounted on front and rear } \\
\text { side of vehicle }\end{array}$ \\
\hline Organ(2) & $\begin{array}{c}\text { Alarm should ring if the } \\
\text { pressure-difference is not within } \\
\text { a specified limit }\end{array}$ & $\begin{array}{c}\text { Alarm should ring if the } \\
\text { distance between the obstacle } \\
\text { and the vehicle is less than a } \\
\text { specified limit }\end{array}$ \\
\hline
\end{tabular}




\begin{tabular}{|c|c|c|}
\hline Physical-Effect(3) & $\begin{array}{c}\text { Velocity of two approaching } \\
\text { vehicles influences the air } \\
\text { pressure between the two } \\
\text { vehicles }\end{array}$ & $\begin{array}{c}\text { Distance between obstacle } \\
\text { and vehicle = f(speed of } \\
\text { vehicle, time lag between } \\
\text { emission and detection of } \\
\text { waves) }\end{array}$ \\
\hline $\begin{array}{c}\text { Physical- } \\
\text { Phenomena(4) }\end{array}$ & $\begin{array}{c}\text { Change in air velocity between } \\
\text { two vehicles creates pressure } \\
\text { difference }\end{array}$ & $\begin{array}{c}\text { Reflection of waves by the } \\
\text { obstacle }\end{array}$ \\
\hline Input(5) & Air Pressure & Sound Energy \\
\hline State-Change(6) & From no signal to danger signal & From no signal to danger \\
signal
\end{tabular}

We now illustrate the process of evaluation of novelty for a design task. Figure 6 shows the highest levels of abstraction at which the concepts, produced in the design task, were found to be different from the most similar existing solutions. Based on this difference, we calculated the following: (a) the levels of abstraction at which these concepts were ideated, and (b) the novelty of each concept (See Table 5). Using Equation-1, $\mathrm{PC}_{1}=\mathrm{PC}_{2}=\mathrm{PC}_{4}=0, \mathrm{PC}_{0}=\mathrm{PC}_{5}=\mathrm{PC}_{6}=1 / 5, \mathrm{PC}_{3}=2 / 5$; using Equation-2, $\mathrm{P}[\mathrm{HNC}]=2 / 5$; and using Equation-3, $\mathrm{N}[\mathrm{NCS}]=(0+6+3+5+3) / 5=3.4$. 


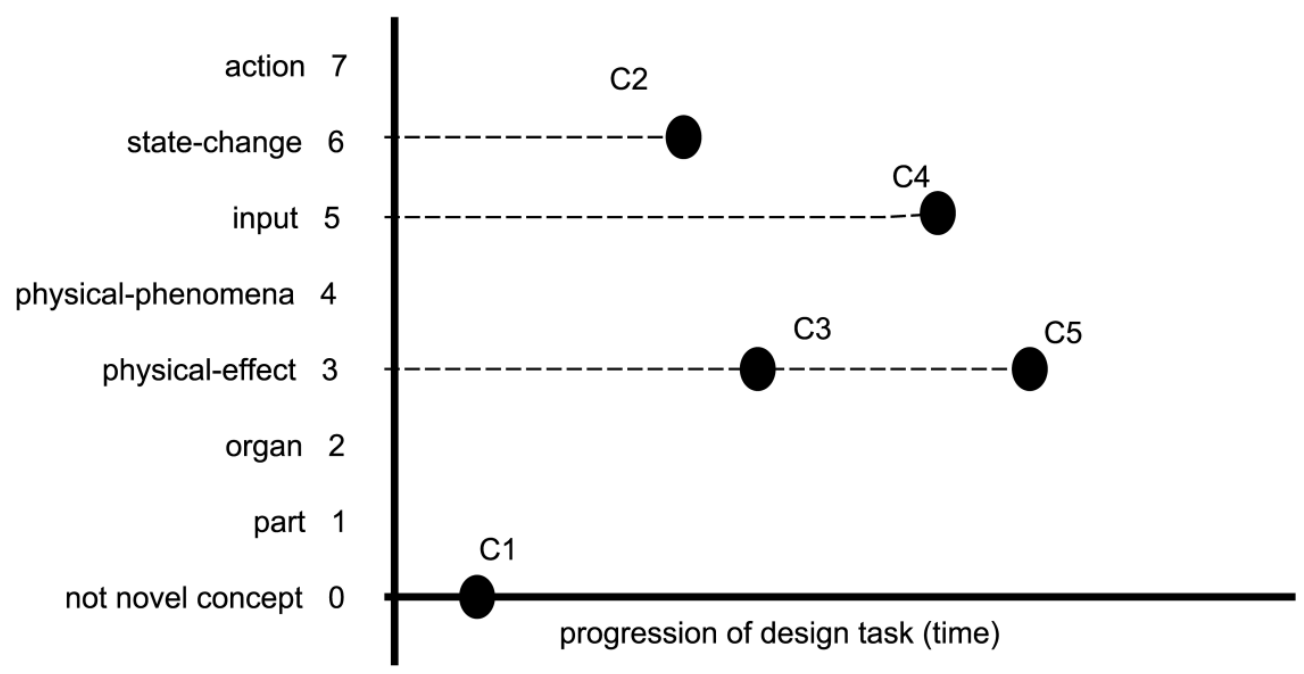

X Axis: Progression of a design task (time)

Y Axis: Highest abstraction level at which a new concept is different from other existing concepts

C1-C5: Concepts produced

Figure 6. An example of evaluation of concepts, using approaches 1 and 2

Table 5: An illustration of evaluation of concepts produced

\begin{tabular}{|c|c|c|c|}
\hline Concept & $\begin{array}{c}\text { Level of abstraction } \\
\text { (x) at which a } \\
\text { concept is ideated }\end{array}$ & $\begin{array}{c}\text { Novelty (using } \\
\text { Approach-1) }\end{array}$ & $\begin{array}{c}\text { Novelty (using } \\
\text { Approach-2) }\end{array}$ \\
\hline C1 & 0 & not novel & 0 \\
\hline C2 & 6 & high-novelty & 6 \\
\hline C3 & 3 & medium-novelty & 3 \\
\hline C4 & 5 & high-novelty & 5 \\
\hline C5 & 3 & medium-novelty & 3 \\
\hline
\end{tabular}

\subsection{Inter-encoder reliability}

An inter-encoder reliability test was carried out for assessment of novelty of design concepts (for Approach-1), and novelty score awarded to each concept (for Approach-2), using the following equation (Blessing and Chakrabarti 2009):

$$
\text { Inter }- \text { Encoder Reliability }=\frac{\text { Number of Agreements }}{\text { NumberofAgreements }+ \text { NumberofDisagreements }}(4)
$$


It was found to be $90 \%$ for both Approaches 1 and 2 (See Appendix-B for details). $70 \%$ or above is the generally accepted threshold for inter-encoder reliability (Blessing and Chakrabarti 2009).

\section{Results}

This section presents the cumulative results for all the studies, individual results for each study, and finally results of testing the hypotheses.

Cumulative results are evaluated statistically using the Wilcoxon Signed-Rank test (http://vassarstats.net/wilcoxon.html). We selected this test because this is a nonparametric test for paired-samples that is used when results are not normally distributed. It is calculated at $\mathrm{n}=16(\mathrm{n}=$ total number of teams $=$ number of teams in each study $\mathrm{x}$ number of studies $=4 \times 4$ ). For two-tailed test, at level-of-significance $p=0.05$, teststatistic $\mathrm{W}_{\text {critical }}=29$ and at $\mathrm{p}=0.02, \mathrm{~W}_{\text {critical }}=23$. The observed value of $\mathrm{W}$ is significant if $\mathrm{W}<\mathrm{W}_{\text {critical. }}$.

Individual results are calculated numerically, due to insufficient data points; this was done only to get indications about probable results. These results are as follows.

\subsection{Proportion of Concepts ideated at abstraction level ' $x$ ' (PCx)}

\subsubsection{Cumulative Results}

Proportion of Concepts ideated at organ level $\left(\mathrm{PC}_{2}\right)$ was significantly higher for biocards than for brainstorming at $95 \%$ confidence-level $\left(\mathrm{W}=26.5\right.$, $\left.\mathrm{p}_{\text {observed }}=0.05\right) . \mathrm{PC}_{1}(\mathrm{~W}=20$, $\left.\mathrm{p}_{\text {observed }}=0.02\right)$ and $\mathrm{PC}_{0}\left(\mathrm{~W}=21, \mathrm{p}_{\text {observed }}=0.02\right)$ were higher for brainstorming than for biocards at $98 \%$ confidence-level. Proportion of concepts ideated at other, higher, 
SAPPhIRE abstraction-levels were not found to be significantly different (for $\mathrm{PC}_{6}, \mathrm{~W}=$ 41.5; for $\mathrm{PC}_{5}, \mathrm{~W}=45$; for $\mathrm{PC}_{4}, \mathrm{~W}=53$; and for $\mathrm{PC}_{3}, \mathrm{~W}=33$ ), even though these were numerically higher for concepts generated for biocards than for brainstorming, as reflected in Figure 7.

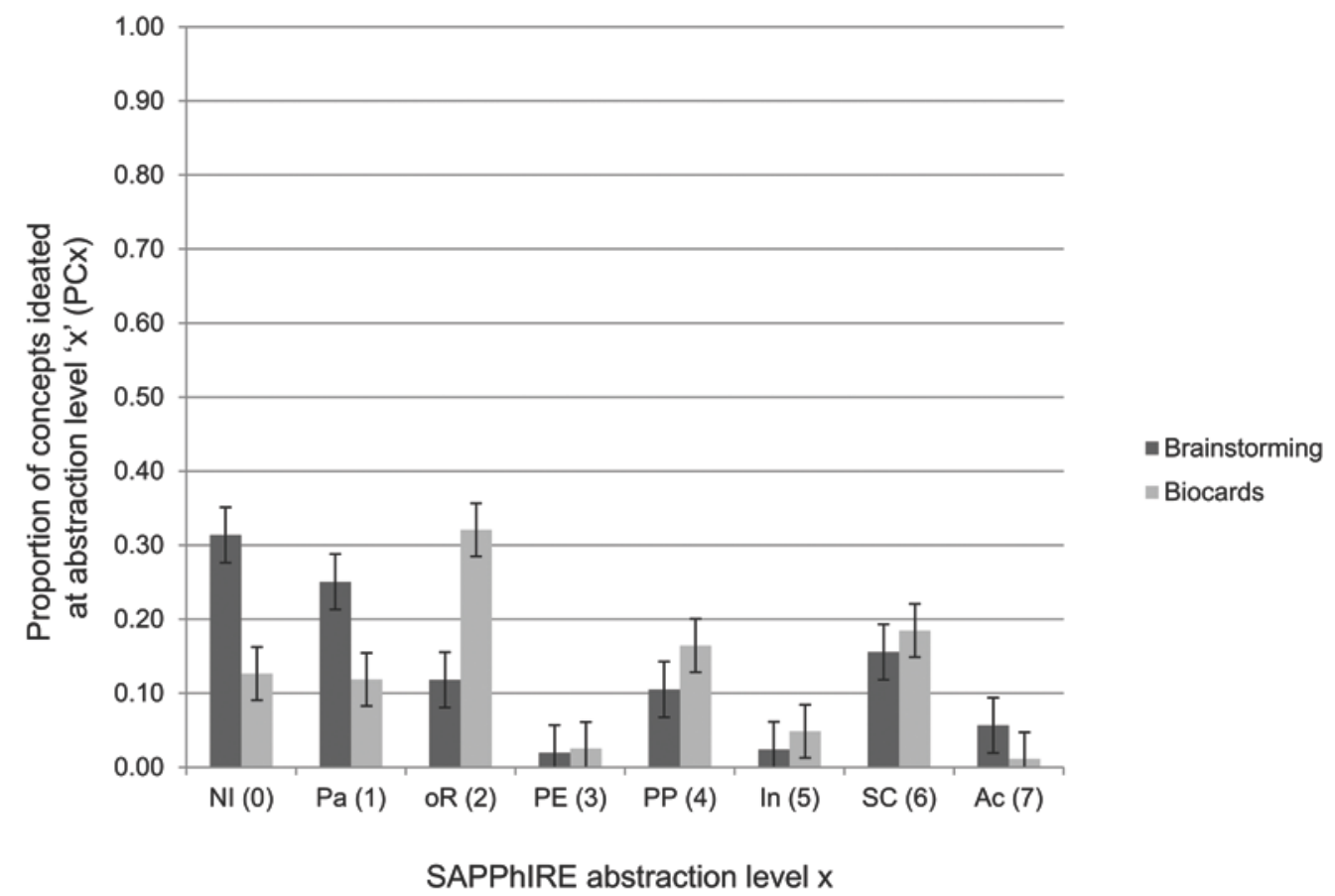

Figure 7. Overall proportion of concepts ideated at abstraction level ' $\mathrm{x}$ ' $\left(\mathrm{PC}_{\mathrm{x}}\right)$ with errorbars at \pm 1 S.E.

\subsubsection{Individual Results}

Figure 8 presents individual results of each study. $\mathrm{PC}_{6}$ and $\mathrm{PC}_{5}$ were higher for designs generated using biocards than those using brainstorming (in 3 out of 4 studies). $\mathrm{PC}_{4}$ and $\mathrm{PC}_{2}$ were higher for designs generated using biocards than those using brainstorming (all studies). $\mathrm{PC}_{1}$ and $\mathrm{PC}_{0}$ were higher for concepts generated using brainstorming than using biocards (all studies). No trend could be found across all four studies for $\mathrm{PC}_{3} . \mathrm{PC}_{7}$ was 
higher for brainstorming than for biocards for Study-1 and Study-2.
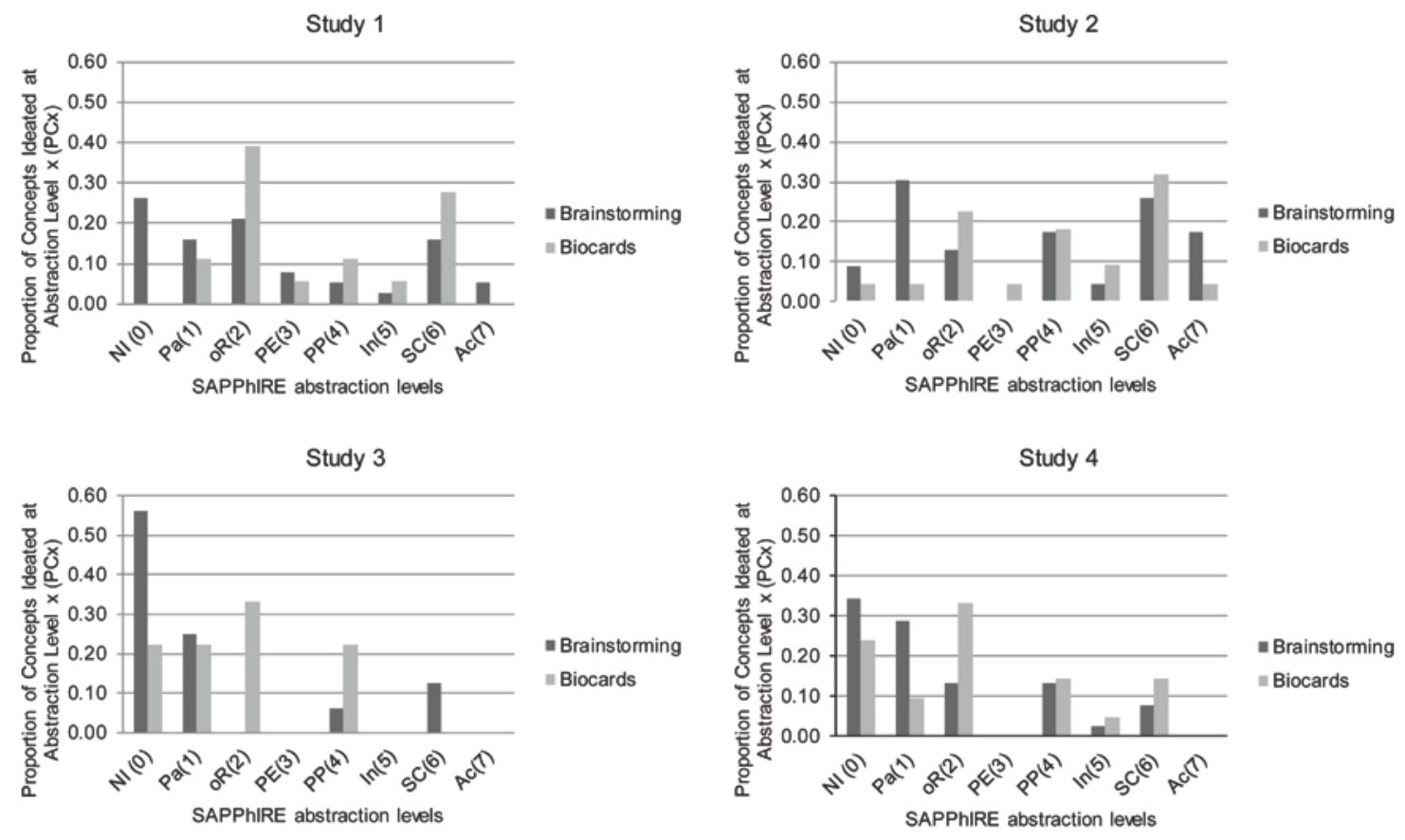

Figure 8. Proportion of concepts ideated at abstraction level ' $\mathrm{x}$ ' $\left(\mathrm{PC}_{\mathrm{x}}\right)$ in Studies 1-4

\subsubsection{Testing hypothesis $h$}

Based on the above results, biocards seem to have produced a higher proportion of solutions (that were ideated at the organ-level) than brainstorming did, in which the concepts were ideated at either part-level or not-ideated. At the other levels of abstraction, no significant difference was found between the concepts produced using the two design methods. Therefore, the difference between biocards and brainstorming, in terms of abstraction levels at which concepts were ideated, has been significant only at lower levels of abstraction. In response to Hypothesis h, biocards helped ideate concepts at higher levels of abstraction than brainstorming did, but not at all the higher SAPPhIRE abstraction levels. One reason for this could be the need for more domain-knowledge and 
experience for ideation at these levels. Another reason could be the variability in motivation and cognitive inspiration because the studies were conducted in three different countries. These reasons are further elaborated in Section 8.

\subsection{Proportion of High-Novelty Concepts P[HNC]}

\subsection{Cumulative Results}

The difference between $\mathrm{P}[\mathrm{HNC}]$ produced using biocards and brainstorming, across all studies, was not statistically significant $(\mathrm{W}=53)$. Figure 9 shows the overall comparison between brainstorming and biocards in terms of $\mathrm{P}[\mathrm{HNC}]$.

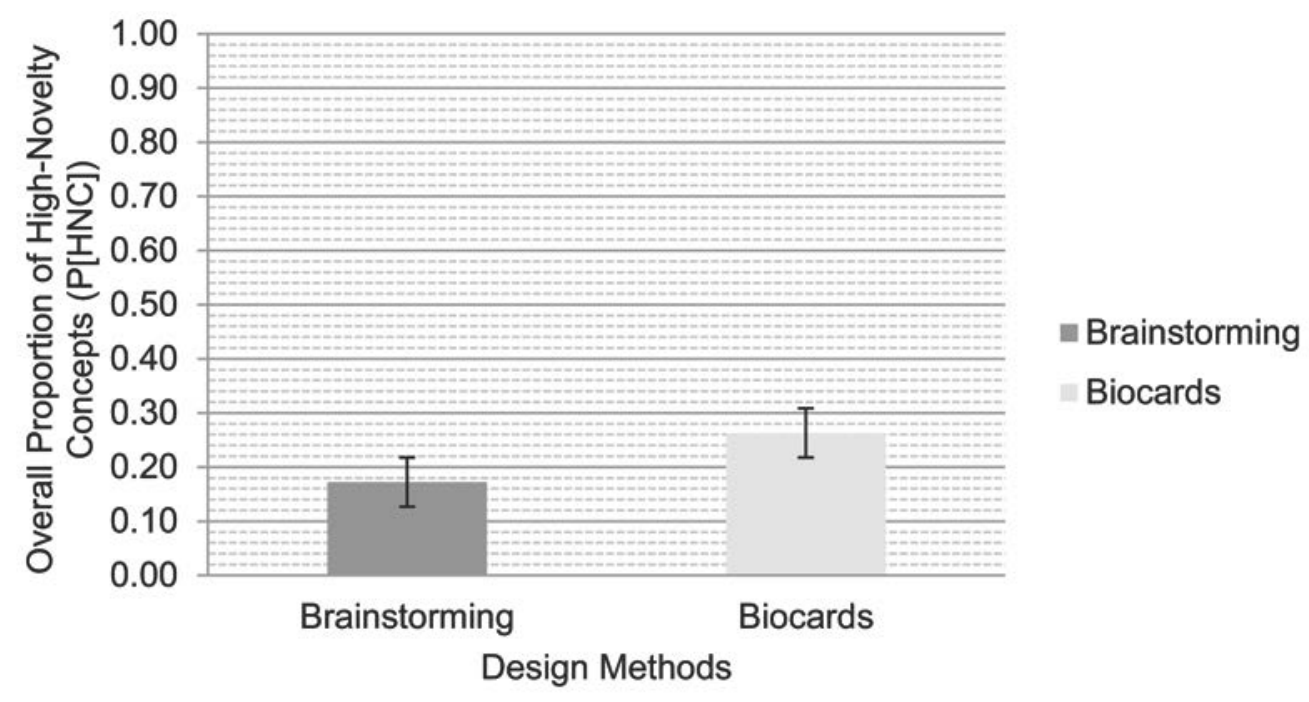

Figure 9. Overall proportion of high-novelty concepts $(\mathrm{P}[\mathrm{HNC}])$ with error-bars at \pm 1 S.E.

\subsubsection{Individual Results}

Figure 10 presents individual results of each study in terms of $\mathrm{P}[\mathrm{HNC}]$. Out of sixteen teams across studies 1-4, $\mathrm{P}[\mathrm{HNC}]$ was higher for biocards in seven teams, and for brainstorming in five teams; four teams did not produce any high novelty concepts. These 
results can at best indicate that biocards are likely to produce designs with higher proportion of highly-novel concepts than brainstorming. However, no strong conclusions could be drawn.
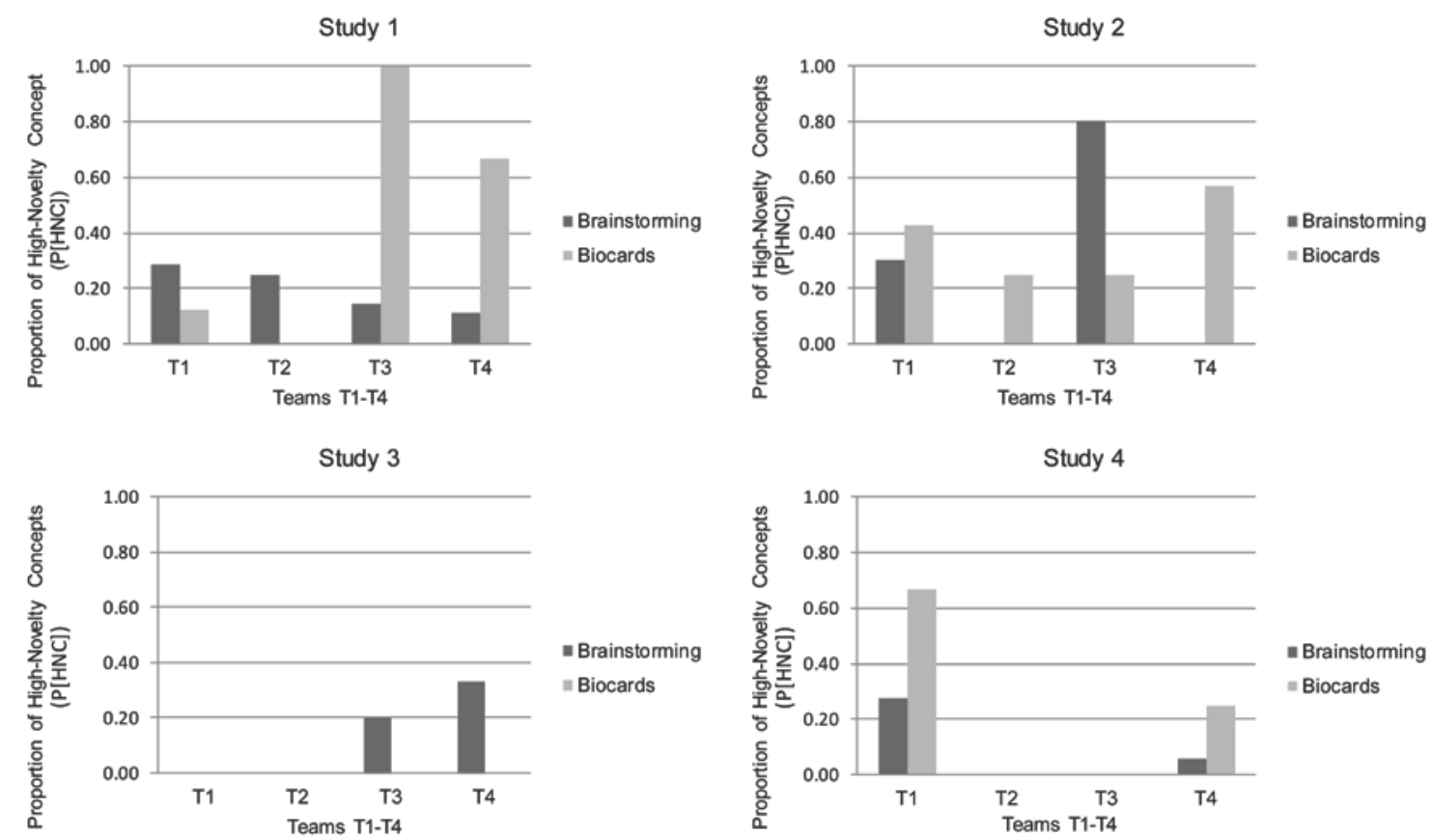

Figure 10. Proportion of high-novelty concepts $(\mathrm{P}[\mathrm{HNC}])$ in studies 1-4

\subsubsection{Testing the hypothesis $H$}

Overall, although $\mathrm{P}[\mathrm{HNC}]$ for biocards was numerically higher, no significant difference could be observed in the proportion of high-novelty concepts produced across biocards and brainstorming. This was because the proportion of concepts ideated at state-change (6) and input (5) level - two of the abstraction-levels accounting for high-novelty concepts, though numerically higher for biocards, was not significantly different between biocards and brainstorming; for action-level (7), the case was opposite: it was numerically higher for brainstorming but the difference not statistically significant (See Section 7.1). 


\subsection{Novelty of New Concept-Space N[NCS]}

\subsubsection{Cumulative Result}

The difference between overall N[NCS], produced using brainstorming and biocards for all studies, was significantly higher for biocards than for brainstorming, at $94.88 \%$ confidence-level $\left(\mathrm{W}=30, \mathrm{p}=0.0512\right.$; here, observed $\mathrm{W}$ is 30 which is close to $\mathrm{W}_{\text {critical }}=$ 29 and observed $\mathrm{p}=0.0512$ which is close to $\mathrm{p}=0.05$, therefore it can be considered that the difference between brainstorming and biocards in terms of $\mathrm{N}[\mathrm{NCS}]$ is somewhat significant). Figure 11 shows the overall comparison between brainstorming and biocards in terms of N[NCS]. Similar results were reported by Ahmed-Kristensen, Christensen and Lenau (2014).

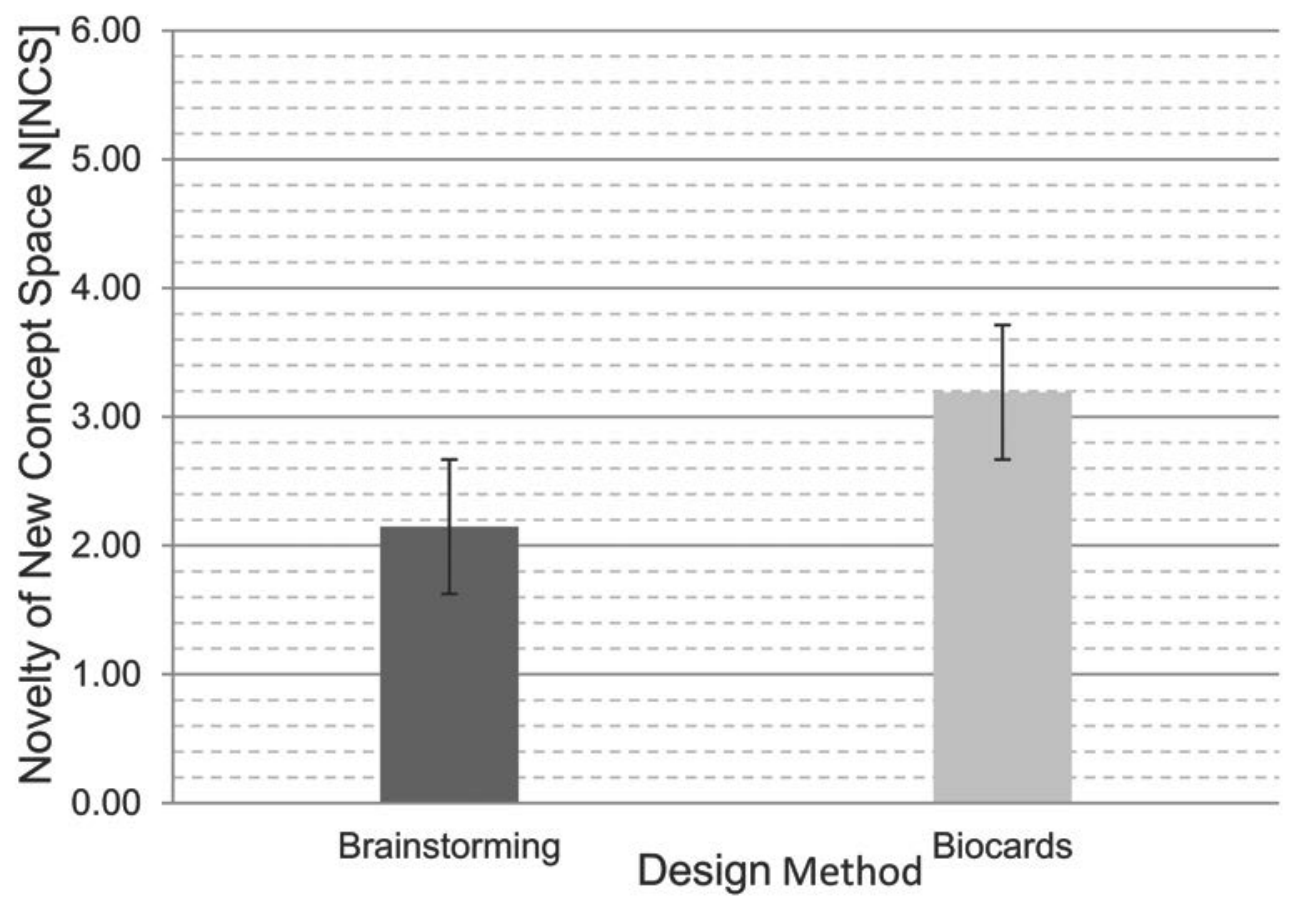


Figure 11. Overall novelty of new concept-space (N[NCS]) with error-bars at \pm 1 S.E.

\subsubsection{Individual Result}

Figure 12 presents, for each study, individual results of comparison between brainstorming and biocards in terms of $\mathrm{N}[\mathrm{NCS}]$. Among sixteen teams, $\mathrm{N}[\mathrm{NCS}]$ was higher for biocards than for brainstorming for eleven teams, indicating that biocards might have more positively influenced novelty of the concepts produced.
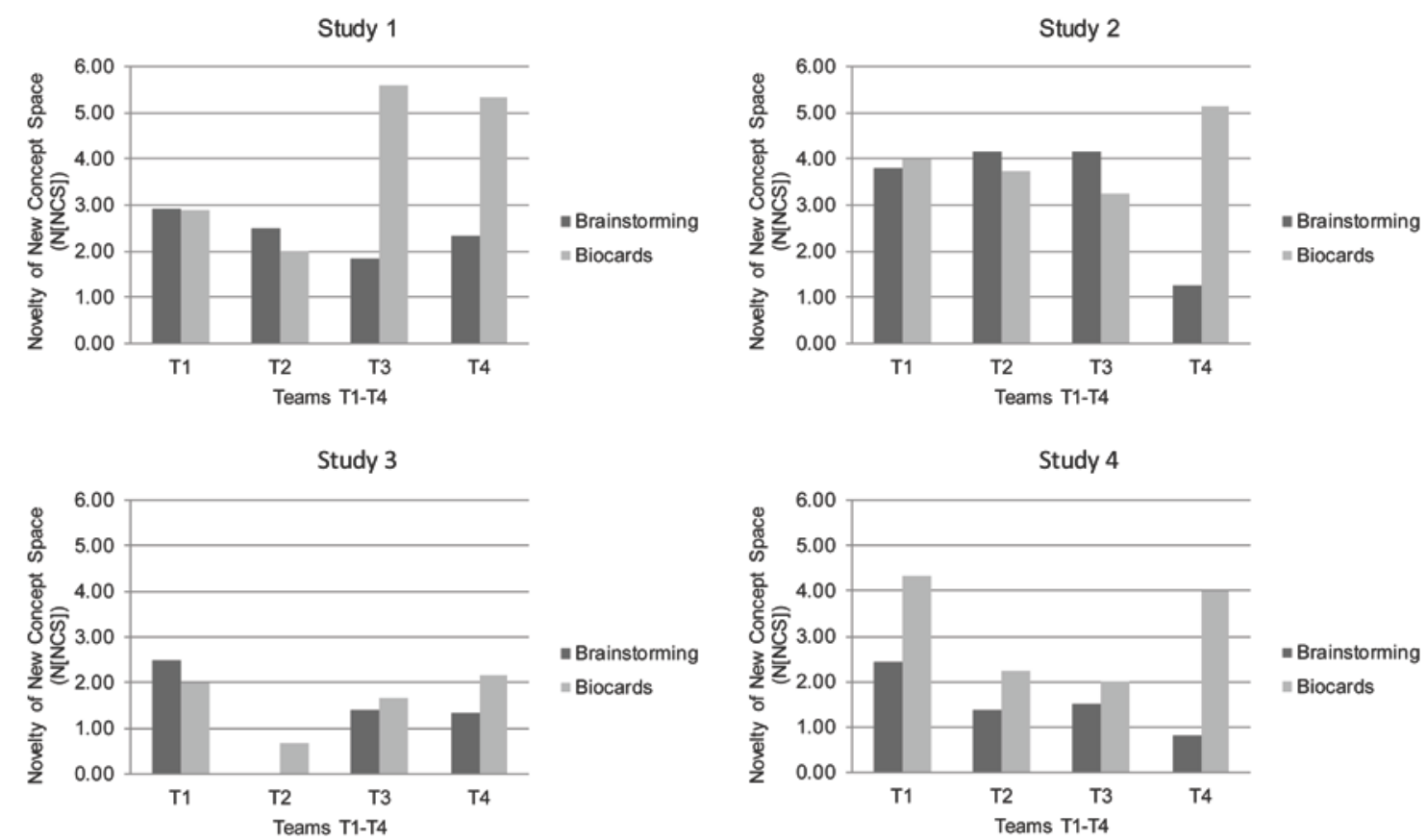

Figure 12. Novelty of new concept-space (N[NCS]) in studies 1-4

\subsubsection{Testing Hypothesis $H$}

Overall, the average novelty of concepts (N[NCS]) generated using biocards was found to be significantly higher than those generated using brainstorming. A significant increase in ideation at organ-level, and some increase in ideation at state-change, input, and physical-phenomena levels seem to have increased novelty of new concept-spaces 
produced in favour of biocards. Therefore, it is argued that concepts generated using biological-analogies in the form of biocards have greater average novelty than concepts generated using brainstorming.

\section{Discussion}

The main results from Section 7 are summarized as follows:

(1) The results in Section 7.1 show that biocards helped ideate concepts at relatively higher levels of abstraction than brainstorming did, even though not at all the higher SAPPhIRE abstraction levels. Thus hypothesis $\mathrm{h}$ (Concepts produced using biological-analogies will be ideated at higher levels of the SAPPhIRE abstraction than those generated using brainstorming) was supported. On the other hand, the result that 'biocards could not support ideation at all the higher abstraction levels', is inline with the results reported in previous studies. For instance, Helms et al. (2009) and Sartori et al. (2010) reported that, in their work, most transfers from biological-analogy to the concept took place at superficial (i.e. lower abstraction) levels only. We suspect two reasons behind this result. The first reason is that, the subjects lacked adequate domain (biological) knowledge and experience. This is also supported by previous studies; for instance, Salgueiredo and Hatchuel (2016) concluded that in order to reach a novel solution, biologically-inspired design requires a special form of collaboration between engineers and biologists; Ozkan and Dogan (2013) found that experienced designers were able to transfer deeper (i.e. more abstract) relations from biological-analogies to design concepts, while novice designers 
transferred superficial (less abstract) aspects of the analogy. The second possible reason is the variability in cognitive inspiration, as the subjects belonged to different countries and therefore had different cultural backgrounds - a factor that has also been reported to influence creativity (Ludwig, 1992; Moalosi, 2007). It is important to take into account these results and underlying reasons in new product development and product re-development processes because of the following. The results highlight that, use of biological-analogies (here, as biocards) over brainstorming would normally lead to incremental increase in abstraction levels of ideation of concepts, which would lead to incremental changes in novelty; however, novelty leaps would not be assured unless factors like adequate experience of designers and team composition were addressed.

(2) The proportion of high-novelty concepts $(\mathrm{P}[\mathrm{HNC}])$ for biocards was not significantly different than that for brainstorming (Section 7.2), but the average novelty of concepts (N[NCS]) generated using biocards was significantly higher than that generated from brainstorming (Section 7.3). In response to Hypothesis $\mathrm{H}$ (Concepts produced using biological-analogies will have a higher level of novelty than concepts produced using brainstorming), it can be said that biocards produced greater average novelty of concepts than brainstorming, while the results are indecisive with respect to the proportion of high novelty concepts. As the basis for evaluation of both $\mathrm{P}[\mathrm{HNC}]$ and $\mathrm{N}[\mathrm{NCS}]$ is the levels of abstraction of ideation of concepts, the reasons behind the results obtained for both $\mathrm{P}[\mathrm{HNC}]$ and N[NCS] are likely to be similar as those for the levels of abstraction. 
One could argue that, extraction of solution-oriented strategies in Task-3 (in the form of biocards) relevant to problems A and B could have advantaged the teams using biocards by giving them more time for concrete ideation over those using brainstorming, where no such strategy was provided. In that case, the design of the experiment would be biased towards biocards. However, the counter-argument is that the teams did not solve the same problem in both Task-3 and Task-5; the biocards made by a team in Task-3 were not the ones used by that team in Task-5, thereby giving no advantage to the team. Therefore the experiment, we argue, is equally fair to both interventions.

Another argument that can be made here is that the development of biocards in the Task-3 session could have served as training in biologically-inspired thinking. However, none of the subjects knew about the biocards earlier. Development of biocards in Task-3 enabled them to effectively use the biocards in Task-5.

It can also be argued that the subjects were positively biased towards biocards. However, we present the following counter-arguments based on four criteria:

(1) Awareness of research goal: The subjects were unaware of the research aim and hypotheses. Also, care was taken to not to emphasize one method over the other, while instructing them for the experiment.

(2) Presentation of information: The way in which the information was presented to the subjects was according to the requirements of the design methods used in this work. The method of biocards required us to give biological phenomena, biological mechanism, functional principle and a sketch on a piece of paper; therefore, these were provided to the subjects as biocards. We argue, therefore, that the influence on results due to presentation of information represents the 
influence of the design methods used. Also, the information presented to the subjects did not contain the hypotheses or the expected results.

(3) Education curriculum: The subjects were mostly designers and not researchers. Based on our experience of the Masters in Design programme at the University Design Department, we feel that they would have been using these design methods for problem solving, rather than studying the design methods themselves - an area of research in creativity in design. Therefore, the subjects knew both the methods as a means for novel idea generation. However, as to which method was likely to produce more novel designs might not have been clear to them.

(4) Assumptions made by the subjects on researcher's preference: Even if the subjects had guessed the researchers' preference, they were not aware of the dimensions (e.g. novelty, usefulness, environmental sustainability, etc.) of the design methods that were under evaluation. However, any assumptions made by the subjects related to the researcher's preference would be based on the previous knowledge of the subjects- the influence of which could not be fully eliminated in studies involving human subjects.

In this work, the session on biocards was conducted after the session on brainstorming. Therefore, it is possible that the knowledge acquired in brainstorming had influenced the concepts produced in biocards. However, literature is ambiguous as to whether exposure to example ideas has a positive or a negative influence on the performance of idea generation. For instance, Pertulla (2006) reviewed literature and concluded that previously generated ideas may positively (Dugosh et al. 2000; Coskun et al. 2000) or negatively (Jansson and Smith 1991; Ziegler et al. 2000) influence idea 
generation. Further, according to Pertulla (2006), subjects first produce common concepts, and only when they run out of these, do they start exploring more novel concepts. However, according to Webster (1996), when there is fatigue, as would be the case in later tasks e.g. using biocards, there is a tendency to over-utilize available cues (thereby sticking to common concepts). Therefore, in this work, it is not clear whether previously generated concepts in brainstorming influenced positively or negatively the newly generated concepts using biocards. The difference in novelty obtained might have been due to the effect of order in which the experiments were conducted. The results could have been more reliable if randomization would have been done to minimize the influence of the order of tasks. Further work could explore this influence.

This work has the following limitations: the studies were conducted in laboratory settings across different countries and subjects and with varied team sizes, with relatively few teams and problems, with only one type of biological stimulus (biocards) and only one type of brainstorming. Further, possible influences of selection of biocards and problems, domain-knowledge and experience and the detail at which a concept was described, could not be ruled out. Also, the measures of evaluation of novelty required comparing the concepts generated with existing solutions found through the Internet. Although a thorough search was conducted to identify existing solutions, the list cannot be claimed to be exhaustive. This might also have influenced the results. This last point suggests the need for future research in building repositories of existing concepts for novelty evaluation. 


\section{Conclusions}

This work aims to compare effects of biomimetics and brainstorming so as to understand the level of significance of biological-analogies as a means of aiding novelty in concepts. This benchmarking has been done for the following units: (a) levels of abstraction at which concepts are ideated; (b) proportion of high-novelty concepts; and (c) average novelty of concepts produced. While unit (a) gives insight into which of the two methods should produce greater novelty, units (b) and (c) are derived from two complementary approaches for measuring novelty. SAPPhIRE model of causality has been used as the basis for measuring the three units. The following are the main outcomes of this work:

- It is for the first time that a representation of biological-analogies (biocards) has been benchmarked with an established method for ideation, in this case brainstorming.

- Designs generated using biocards showed an incremental increase in novelty of concepts produced compared to when brainstorming was used for ideation; however, large novelty leaps were not observed.

- Despite the session on biocards being conducted after the session on brainstorming, subjects were unable to ideate using biocards at all the higher levels of SAPPhIRE abstraction. This indicates the need for training and experience in using biological-analogies for designing.

- In line with earlier research, this study demonstrates that design methods do influence novelty of concepts; this, therefore, calls for careful selection of design methods based on the requirements of the design under consideration. 
Future work includes the following: a) more detailed studies with randomization of design methods and problems; b) comparison of biomimetics using other representations, with other creativity approaches, and using other metrics for novelty measurement; and c) studying the influence, on results, of having interdisciplinary team members and experts as subjects.

\section{Acknowledgements}

Authors are thankful to Siddharth L, Sanket Kamble, Praveen Uchil, Kumari MC and Nitin Nazkani for assisting in this research.

\section{Appendix-A: Existing Solutions}

Evaluation approaches 1 and 2 are based on (Sarkar and Chakrabarti, 2011) and (Srinivasan and Chakrabarti, 2010), who used the Internet to create a database of existing solutions in these approaches. To validate these approaches, the novelty of concepts assessed using the approaches were compared with that assessed by experts, which were found to have strong correlations. As the approaches are already validated, these have been used directly in our work.

It is to be noted that, in this work, the database was not created by searching for specific existing solutions or problem functionalities from the Internet, but by keyword search in Google which allowed us to expand our database to include solutions that were originally unknown to us. The keywords were generated using the following as stimuli: (a) problem description; and (b) concepts under evaluation. While the keyword generated from stimulus (a) allowed us to find generic solutions related to the problem, stimulus (b) ensured that at least such solutions that are most similar to the concepts produced in the studies are populated. Collecting most similar solutions for a particular concept is important for evaluation of novelty because it is only by comparing a concept with such solutions, that its newness (novelty) can be correctly determined. Therefore, we argue that, even though the database cannot be claimed to be complete, it was appropriately populated, such that concepts produced in this research could be fairly evaluated.

For problem A, for the function given in the problem, the following 16 existing solutions and 2 patents were found from the internet: crumple-zones, air-bags, seat-belts, padding-edges, autonomous-cars, collapsible-steering, front- and rear-bumpers, life-guard in trams, cargo-barrier, 
shock-absorbers, helmet, armours, safety-gloves, electromagnetic-repulsion in cars, CA 2725057 A1, US 6565147 B1.

Similarly, for Problem B, the following 12 existing solutions were found: silver-screens, windows with overhangs, windows with awnings, reflective-shades, blinds, curtains, solar-screens, electronically-dimmable devices - suspended-particle devices and micro-blinds, mechanical smart-windows, tilted-windows, windows with photosensitive-glazing.

\section{Appendix-B: Inter-encoder Reliability Test}

In this work, encoding has been done by one encoder and compared with encoding done by the researcher (the first author). The encoder used for inter-encoder reliability in this work is a $\mathrm{PhD}$ student in a university design department, with Bachelors in Mechanical Engineering and Masters in Design. While the encoder had five years of experience in using SAPPhIRE-model, the researcher had three years in using SAPPhIRE model, when the test was conducted.

For one of the problems of this study, concepts produced by a team, using both brainstorming and biocards, were given to the encoder. These concepts constituted $7 \%$ of the total concepts that were produced in studies 1-4. To eliminate encoder bias, all the concepts were sequentially labelled and the information on design method using which these concepts were produced was not provided. The encoder was then asked to encode those concepts.

For evaluation of novelty of these concepts, the encoder was also given a list of existing solutions (See Appendix-A) in society that authors had searched from the Internet. The encoder was asked to create SAPPhIRE models (both concepts produced in design tasks and existing solutions) and then evaluate novelty of concepts produced using both approaches 1 and 2 .

For Approach-1, the number of agreements between the encodings done by the encoder and the researcher was assessed in terms of the number of design concepts that were assessed to be of the same level of novelty (i.e. high- or medium- or low-novelty) by the encoder and the researcher; and the number of disagreements was assessed in terms of number of concepts that were not assessed to be of the same level of novelty. Inter-encoder reliability was initially found to be $60 \%$. The following were the disagreements between the researcher and the encoder:

(1) $30 \%$ of the concepts were encoded as 'highly novel' by the researcher but as 'medium novelty' by the encoder. This disagreement occurred due to the following reasons: a) for $20 \%$ of the concepts, while the researcher created two instances of SAPPhIRE models, the encoder created single instance SAPPhIRE model; and $b$ ) for remaining $10 \%$ of the 
concepts, disagreement occurred due to different interpretation of state-change by the encoder and the researcher;

(2) $10 \%$ of the concepts were encoded as 'highly novel' by the researcher but as 'low novelty' by the encoder. This happened because of misinterpretation of input as part.

After discussion with the encoder on disagreements, the inter-encoder reliability was then found to be $90 \%$. While the disagreement (1) was resolved after discussion and the encoder agreed to the codification done by the researcher, disagreement (2) could not be resolved.

For Approach-2, the number of agreements was assessed in terms of the number of concepts that were assigned the same novelty score (0-7) by the encoder and the researcher; and the number of disagreements was assessed in terms of number of concepts that were assigned different novelty scores. Inter-encoder reliability was initially found to be $40 \%$. The following were the disagreements between the researcher and the encoder:

(1) $20 \%$ of the concepts were assigned novelty score ' 0 ' by the researcher but ' 2 ' by the encoder. This happened because of incorrect identification of organ in those concepts;

(2) $30 \%$ of the concepts were assigned novelty score ' 6 ' by the researcher but ' 4 ' by the encoder. This disagreement occurred due to the following reasons: a) for $20 \%$ of the concepts, while the researcher created two instances of SAPPhIRE models, the encoder created single instance SAPPhIRE model; and b) for $10 \%$ of the concepts, there was difference in interpretation of state-change between the encoder and the researcher.

(3) $10 \%$ of the concepts were assigned novelty score ' 5 ' by the researcher but ' 1 ' by the encoder. This happened because of misinterpretation of input as part.

After discussion with the encoder on disagreements, the inter-encoder reliability was then found to be $90 \%$. While the disagreements (1) - (2) were resolved after discussion and the encoder agreed to the codification done by the researcher, disagreement (3) could not be resolved.

Please note the two disagreements (point 2 for Approach-1 and point 3 for Approach-2) arose from the same concept, and are therefore, same. This disagreement remained after discussion because of the following reason: according to the researcher, the 'input' construct in the SAPPhIRE model of the design concept was different from 'input' constructs in the SAPPhIRE models of the existing solutions. Therefore, the researcher encoded it as 'highly novel' and awarded it a novelty score of ' 5 '. However, the same 'input' existed as 'part' construct in an existing-solution. The encoder, therefore, evaluated the concept as 'low novelty' and assigned it a novelty score of ' 1 '. 


\section{References}

Ahmed-Kristensen, Saeema, Bo. Thomas. Christensen, and Torben Anker Lenau. 2014. "Naturally Original: Stimulating Creative Design through Biological-Analogies and Random Images." Proceedings of the 13th International Design Conference, Design Society, 427-436, Croatia, May 19-22.

Al-khatib, Bilal Adel. 2012. "The Effect of Using Brainstorming Strategy in Developing Creative Problem Solving Skills among Female Students in Princess Alia University College." American International Journal of Contemporary Research 2 (10): 29-38.

Appio, Francesco Paolo, SofianeAchiche, Antonella Martini, and Catherine Beaudry. 2016. "On Designers' Use of Biomimicry Tools During the New Product Development Process: An Empirical Investigation." Technology Analysis \& Strategic Management. 1-15. doi: 10.1080/09537325.2016.1236190

Baldussu, Alessandro, and Gaetano Cascini. 2015. "About Integration Opportunities between TRIZ and Biomimetics for Inventive Design." Procedia Engineering 131: 3-13.https://doi.org/10.1016/j.proeng.2015.12.342

Bhushan, Bharat. 2016. Biomimetics: Bioinspired Hierarchical-Structured Surfaces for Green Science and Technology. Heidelberg : Springer.

Blessing, Lucienne TM, and Amaresh Chakrabarti. 2009. DRM, A Design Research Methodology. Verlag: Springer.

Bonnardel, Nathalie. 2000. "Towards Understanding and Supporting Creativity in Design: Analogies In A Constrained Cognitive Environment." Knowledge-Based Systems 13 (7): 505-513. https://doi.org/10.1016/S0950-7051(00)00067-8 
Braun, R. J. and Fitt, D. 2003. "To minimise shear stress and to avoid solid to solid contact between the eyelid and the eye surface, the latter is covered by a thin tear film." Math Med Biol 20, 1-28.

Chakrabarti, Amaresh, Prabir Sarkar, B. Leelavathamma, and B. S. Nataraju. 2005. "A Functional Representation for Aiding Biomimetic and Artificial Inspiration of New Ideas." Artificial Intelligence for Engineering Design, Analysis and Manufacturing 19 (02): 113-132.doi: 0.1017/S0890060405050109.

Cheong Hyunmin, Ivey Chiu, Lee Shu, Robert, B. Stone, and Daniel A. McAdams. 2011."Biologically Meaningful Keywords for Functional Terms of the Functional Basis." Journal of Mechanism Design. 133(2): 021007. doi:10.1115/1.4003249.

Cheong, Hyunmin, and Lee Shu. 2012. "Automatic Extraction of Causally Related Functions from Natural-Language Text for Biomimetic Design." Proceedings of the ASME 2012 international design engineering technical conferences \& computers and information in engineering conference, 373-382.August 15-18.

Chulvi, Vicente, Elena Mulet, Amaresh Chakrabarti, Belinda López-Mesa, and Carmen González-Cruz. 2012. "Comparison of the Degree of Creativity in the Design Outcomes Using Different Design Methods." Journal of Engineering Design, 23(4): 241-269. doi: 10.1080/09544828.2011.624501

Coskun, Hamit, Paul B. Paulus, Vincent Brown, and Jeffrey J. Sherwood. 2000. "Cognitive Stimulation and Problem Presentation in Idea-Generating Groups." Group Dynamics: Theory, Research, and Practice 4(4): 307-329. doi:10.1037/1089-2699.4.4.307.

Craig, Salmaan, David Harrison, Andrew Cripps, and Daniel Knott. 2008. "Biotriz suggests Radiative Cooling of Buildings can be done Passively by Changing the 
Structure of Roof Insulation to let Longwave Infrared Pass." Journal of Bionic Engineering 5(1): 55-66. doi: 10.1016/S1672-6529(08)60007-4.

Dahl, Darren W., and Page Moreau. 2002. "The Influence and Value of Analogical Thinking During New Product Ideation." Journal of Marketing Research 39 (1): 47-60.doi: http://dx.doi.org/10.1509/jmkr.39.1.47.18930.

Deldin, Jon-Michael, and Megan Schuknecht. 2014. "The Asknature Database: Enabling Solutions in Biomimetic Design." Chap 2 in Biologically Inspired Design. London: Springer.

Dugosh, Karen Leggett, Paul B. Paulus, Evelyn J. Roland, and Huei-Chuan Yang. 2000. "Cognitive Stimulation in Brainstorming." Journal of Personality and Social Psychology. 79 (5): 722-735.

Etoundi, Appolinaire C., Stuart C. Burgess, and Ravi Vaidyanathan. 2013. "A BioInspired Condylar Hinge for Robotic Limbs." Journal of Mechanisms and Robotics 5 (3): 031011. doi: 10.1115/1.4024471.

Fernald, Lloyd W., and Pam Nickolenko. 1993. "The Creative Process: Its Use and Extent of Formalization by Corporations." The Journal of Creative Behavior 27 (3): 214-220. doi: 10.1002/j.2162-6057.1993.tb00708.x

Helms, Michael, Swaroop S Vattam, and Ashok K Goel. 2009. "Biologically Inspired Design: Process and Products." Design Studies, 30(5), 606622.https://doi.org/10.1016/j.destud.2009.04.003

Helms, Michael, E., and Ashok K Goel 2012. "Analogical Problem Evolution In Biologically Inspired Design." Design Computing and Cognition '12. Springer, Dordrecht, June 7-9. 
Herring, Scarlett R., Brett R. Jones, and Brian P. Bailey. 2009. "Idea Generation Techniques among Creative Professionals." System Sciences, 2009. HICSS'09. Hawaii International Conference. IEEE, January 5-8.

Isaksen, Scott G. 1998. A Review of Brainstorming Research: Six Critical Issues for Inquiry. Creative Research Unit, Creative Problem Solving Group-Buffalo.

Jansson, David G., and Steven M. Smith. 1991. "Design Fixation." Design Studies 12 (1): 3-11. https://doi.org/10.1016/0142-694X(91)90003-F

Kaiser, M. K., H. Hashemi Farzaneh, and Udo Lindemann. 2012. "An Approach to support Searching for Biomimetic Solutions based on System Characteristics and its Environmental Interactions", Proceedings of the 12th International Design Conference, Design Society, Dubrovnik, Croatia, May 21- 24.

Kennedy, Brook, and Jacquelyn KS, Nagel James. 2015."Integrating Biology, Design, and Engineering for Sustainable Innovation." Proceedings of the Integrated STEM Education Conference (ISEC), IEEE, 88-93, March 7.

Keshwani, Sonal, Torben Anker Lenau, Saeema Ahmed-Kristensen, and Amaresh Chakrabarti. 2013."Benchmarking bio-inspired designs with brainstorming in terms of novelty of design outcomes." Proceedings of the 19th International Conference on Engineering Design, Seoul Korea August 19-22.

Lenau, T., Andy Dentel, P. Ingvarsdóttir, and T. Guđlaugsson. 2010. "Engineering Design of an Adaptive Leg Prosthesis using Biological Principles." Proceedings of the 11th International Design Conference, Dubrovnik, Croatia.

Lopez-Mesa, Belinda, Elena Mulet, Rosario Vidal, and Graham Thompson. 2011. "Effects of Additional Stimuli on Idea-Finding in Design Teams." Journal of Engineering Design 22 (1): 31-54. http://dx.doi.org/10.1080/09544820902911366 
Lepora, Nathan F., Paul Verschure, and Tony J. Prescott. 2013. "The State of the Art in Biomimetics." Bioinspiration \& Biomimetics. 8(1): 013001.

Ludwig, Arnold, M. 1992."Culture and Creativity." American Journal of Psychotherapy. 46(3): 454-469.

Molina, Arturo, Ahmed H. Al-Ashaab, Timothy IA Ellis, Robert IM Young, and Robert Bell. 1995. "A Review of Computer-Aided Simultaneous Engineering Systems." Research in Engineering Design 7 (1): 38-63.doi:10.1007/BF01681911.

Moss Jr, Jerome. 1966. "Measuring Creative Abilities in Junior High School Industrial Arts." Monograph 2.

Moalosi, Richie, 2007. The Impact of Socio-Cultural Factors Upon Human-Centred Design In Botswana, PhD diss., Queensland University of Technology.

Murphy, Jeremy, Katherine Fu, Kevin Otto, Maria Yang, Dan Jensen, and Kristin Wood. 2014. "Function Based Design-By-Analogy: A Functional Vector Approach to Analogical Search." Journal of Mechanical Design 136 (10): 101102. doi: $10.1115 / 1.4028093$

Nagel, Jacquelyn KS, Robert L. Nagel, Robert B. Stone, and Daniel A. McAdams. 2010. "Function-Based, Biologically Inspired Concept Generation." Artificial Intelligence for Engineering Design, Analysis and Manufacturing, 24(04): 521535. https://doi.org/10.1017/S0890060410000375

Nelson, Brent, Jamal Wilson, and Jeannette Yen. 2009. "A Study of Biologically-Inspired Design as a Context for Enhancing Student Innovation". Proceedings of the 39th IEEE Frontiers in Education Conference, October 18-21. 
Osborn, A. F., G. Rona, P. Dupont, and L. Armand. 1971. "The Constructive Imagination: How to take Advantage of its Ideas, Principles and Process of the Creative Thought and Brainstorming." Dunod, Paris.

O'Rourke, Julia M., and Carolyn C. Seepersad. 2015. "Toward a Methodology for Systematically Generating Energy-and Materials-Efficient Concepts Using Biological Analogies." Journal of Mechanical Design 137(9): 091101. doi: $10.1115 / 1.4030877$

Ottosson, Stig.1995. "Boosting Creativity in Technical Development." Workshop in Engineering Design and Creativity, 35-39. Pilsen, Czech Republic.

Ozkan, Ozgu, and FehmiDogan. 2013. "Cognitive Strategies of Analogical Reasoning in Design: Differences between Expert and Novice Designers." Design Studies 34(2): 161-192. https://doi.org/10.1016/j.destud.2012.11.006

Pahl, Gerhard, and Wolfgang Beitz.2007. Engineering Design A systematic Approach. Berlin: Springer.

Perttula, MattiKalevi. 2006. "Idea Generation in Engineering Design: Application of a Memory Search Perspective and some Experimental Studies." PhD diss., Helsinki University of Technology.

Ranjan, B.S.C. Srinivasan Venkataraman, and Amaresh Chakrabarti. 2012. "The Extended, Integrated Model of Designing." Proceedings of the Tools and Methods of Competitive Engineering, Karlsruhe, Germany, May 7-11.

Rhodes, Mel. 1961. "An analysis of creativity." The Phi Delta Kappan 42(7): 305-310.

Salgueiredo, Camila Freitas, and Armand Hatchuel. 2016. "Beyond Analogy: A Model of Bioinspiration for Creative Design." Artificial Intelligence for Engineering 
Design, Analysis and Manufacturing, 30(02):159-170.

doi:10.1017/S0890060416000044

Sara, Khelil, and Zemmouri Noureddine. 2015."A Bio Problem-Solver for Supporting the Design, Towards the Optimization of the Energy Efficiency." Modeling, Simulation, and Applied Optimization (ICMSAO), 2015, 1-6. IEEE

Sarkar, Prabir, and Amaresh Chakrabarti. 2008. "Studying Engineering Design Creativity-Developing A Common Definition and Associated Measures." In Studying design creativity Edited by John Gero, Springer:Verlag.

Sarkar, Prabir, and Amaresh Chakrabarti. 2011. "Assessing Design Creativity." Design Studies. 32(4): 348-383. doi: 10.1016/j.destud.2011.01.002

Sartori, Julian, Ujjwal Pal, and Amaresh Chakrabarti. 2010. "A Methodology For Supporting "Transfer” in Biomimetic Design." Artificial Intelligence for Engineering Design, Analysis and Manufacturing 24 (04): 483-506. https://doi.org/10.1017/S0890060410000351

Srinivasan, V, and Amaresh Chakrabarti. 2010. "Investigating Novelty-Outcome Relationships in Engineering Design." Artificial Intelligence for Engineering Design, Analysis and Manufacturing 24(02): 161-178. doi: 10.1017/S0890060410000351

Sternberg, Robert J., and Todd I. Lubart 1999. "The Concept of Creativity: Prospects and Paradigms." In Handbook of creativity Chap 1, edited by Robert J. Sternberg, 315, Cambridge: Cambridge University Press.

Taleb, Ahmed, Hassan Hamza, and Eman Wefky. 2013 "The Effect of Using Brainstorming Strategy on Developing Creative Thinking Skills for Sixth Grade Students in Science Teaching." Proceedings of International Conference on e- 
Learning "Best Practices in Management, Design and Development of e-Courses: Standards of Excellence and Creativity" IEEE, May 7-9.

Tsenn, Joanna, Julie S. Linsey, and Daniel A. McAdams. 2016. "Bioinspired Materials Design: An Assessment of Methods to Improve a Text Mining Algorithm for Identifying Biological Material Structural Design Principles." Proceedings of ASME 2016 International Design Engineering Technical Conferences \& Computers and Information in Engineering Conference, North Carolina, USA, August 21-24.

Vincent, Julian FV, Olga A. Bogatyreva, Nikolaj R. Bogatyrev, Adrian Bowyer, and Anja-Karina Pahl. 2006. "Biomimetics: Its Practice and Theory." Journal of the Royal Society Interface 3(9): 471-482. doi: 10.1098/rsif.2006.0127.

Vattam, Swaroop, Bryan Wiltgen, Michael Helms, Ashok K. Goel, and Jeannette Yen. 2011. "DANE: Fostering Creativity in and through Biologically Inspired Design." In Design Creativity 2010 edited by Toshiharu Taura, 115-122. Springer.

Walls, Gordon Lynn. 1942. The vertebrate eye and its adaptive radiation. Bloomfield Hills, Mich., Cranbrook Institute of Science

Ward, Thomas B. 1998. "Analogical Distance and Purpose in Creative Thought: Mental Leaps Versus Mental Hops." In Advances in analogy research: Integration of theory and data from the cognitive, computational, and neural sciences: 221230.Sofia: New Bulgarian University

Webster, Donna M., Linda Richter, and Arie W. Kruglanski. 1996. "On Leaping to Conclusions when Feeling Tired: Mental Fatigue Effects on Impressional Primacy." Journal of Experimental Social Psychology 32 (2): 181-195. 
Ziegler, Rene, Michael Diehl, and Gavin Zijlstra. 2000. "Idea Production in Nominal and Virtual Groups: Does Computer-Mediated Communication Improve Group Brainstorming?" Group Processes \& Intergroup Relations 3 (2): 141-158. 